\title{
Am I My Brother's Barkeeper? Sibling Spillovers in Alcohol Consumption at the Minimum Legal Drinking Age*
}

\author{
Eunju Lee \\ University of California, Davis \\ Geoffrey C. Schnorr \\ California Policy Lab at UCLA \\ State of California Employment Development Department
}

November 26, 2022

\begin{abstract}
We use data on siblings near the minimum drinking age to provide causal estimates of peer effects in alcohol consumption, exploiting the increase in consumption of the older sibling in a regression discontinuity design. Preferred point estimates imply that younger sibling binge drinking decreases at the cutoff. These negative reduced form spillover effects are concentrated in subgroups where the first stage discontinuity is largest, among siblings who are likely to spend more time together, and for measures of excessive alcohol consumption. While our results are somewhat imprecise, we argue that these patterns of heterogeneity are consistent with younger siblings learning from the costs of their older siblings' drinking behavior. Our results are directly interpretable as the effect of peer alcohol consumption, whereas most prior work identifies the effect of exposure to the peer. We explain how this distinction matters for policy.
\end{abstract}

\footnotetext{
*Lee: ejulee@ucdavis.edu. Schnorr: gcschnorr@ucdavis.edu. We are thankful for guidance from Marianne Bitler, Scott Carrell, Marianne Page, Brendan Price, and Monica Singhal. We also thank Kitt Carpenter, Partha Deb, Chloe East, Emiliano Huet-Vaughn, Krzysztof Karbownik, Konstantin Kunze, Derek Rury, and Justin Wiltshire for helpful comments and conversations. Schnorr gratefully acknowledges financial support for this work from the Bilinski Educational Foundation. Lee has nothing to disclose.
} 


\section{Introduction}

Excessive alcohol consumption has been shown to harm young adults in a variety of dimensions including health, educational performance, criminal activity, and criminal victimization (Carpenter and Dobkin, 2009; Carrell et al., 2011; Lindo et al., 2013; Carpenter and Dobkin, 2015, 2017; Chalfin et al., forthcoming). Among the many potential determinants of adolescent alcohol use, peer effects have received substantial attention from academics and policymakers. ${ }^{1}$

Leading empirical work provides evidence for positive peer effects in alcohol consumption via quasi-random assignment to college roommates (Duncan et al., 2005; Eisenberg et al., 2014; Guo et al., 2015) or primary/secondary school cohort-mates (Argys and Rees, 2008) who consume more alcohol. While convincing, such designs cannot be replicated in many other peer groups of interest, notably siblings. A rapidly growing literature has used natural experiments to demonstrate the importance of sibling influences in a variety of important domains ${ }^{2}$ and strong positive correlations in sibling alcohol consumption are well-established in the public health literature (Duncan et al., 2001; Fagan and Najman, 2005; Trim et al., 2006; Van Der Vorst et al., 2007; Whiteman et al., 2013). However, causally interpretable estimates of sibling spillovers in alcohol consumption are virtually non-existent. ${ }^{3}$

This paper provides causally interpretable estimates of peer effects in alcohol consumption between siblings. We focus on siblings residing in the same household and exploit a discontinuous increase in older sibling alcohol consumption at the minimum legal drinking age (MLDA) using a regression discontinuity design (RDD). Our results are, to our knowledge, the first quasiexperimental estimates of peer effects in alcohol consumption between siblings.

Attempts to estimate causal peer effects face four main difficulties. First, the "reflection" problem implies that a simple regression of peer A's behavior on peer B's cannot determine the direction of the effect (Manski, 1993). Second, peer groups are typically endogenous, which is a concern if individuals choose peers who have similar preferences. Third, peers are likely to experience unobservable common shocks which are correlated with their outcomes. Finally, since many research designs rely on variation in exposure to peers (and not peer behavior directly), researchers are often unable to determine whether a spillover effect is the result of the peer behavior of interest or some correlated peer characteristic - they are "contextual" as

\footnotetext{
${ }^{1}$ In its Underage Drinking Fact Sheet, the National Institute of Alcohol Abuse and Alcoholism lists peer pressure as one of three key causes of alcohol consumption among adolescents (https://pubs.niaaa.nih.gov/publications/UnderageDrinking/UnderageFact.htm).

${ }^{2}$ Including, for example, smoking (Harris and López-Valcárcel, 2008), health outcomes (Breining, 2014; Ho, 2017; Cawley et al., 2019; Daysal et al., 2019), fertility (Heissel, 2021), and education (Goodman et al., 2015; Joensen and Nielsen, 2018; Karbownik and Özek, 2019; Altmejd et al., 2021)

${ }^{3}$ The economic literature on this question that we are aware of is limited to Altonji et al. (2016), whose empirical approach (a joint dynamic probit model) relies on the assumption that any unobserved confounding variable correlated with the alcohol consumption of both siblings is time invariant.
} 
opposed to "contagion" effects (Manski, 2000; Argys and Rees, 2008). Contagion effects create social multipliers in the behavior of interest (an intervention that reduces one person's alcohol consumption also reduces their peers'), while contextual effects may not.

Our setting and identification strategy address each of these difficulties. By focusing on siblings, a peer group which is naturally occurring, we avoid the potential for selection into the peer group. By restricting the sample to siblings with different ages, we ensure that the variation in alcohol consumption that we utilize is both exogenous (avoiding the problem of common shocks) and specific to one of the two siblings (avoiding the reflection problem). Since our identification strategy provides variation in the older sibling's alcohol consumption directly, we isolate contagion effects without any additional identification assumptions.

We utilize data from the 1997 National Longitudinal Survey of Youth (NLSY97), which has two key features for our analyses. First, the data contains unique "household roster" information on all individuals living with the NLSY97 respondent. These rosters include the birth months of each household member and their relationship to the respondent. Second, it contains several high frequency (past month) measures of alcohol consumption.

In the full sample of 4,278 sibling-pair-years, our estimates imply a negative relationship between the older sibling's legal access to alcohol and the younger sibling's alcohol consumption. The preferred specification implies that the number of binge drinking days ( 5 or more drinks) in the past 30 days reported by younger siblings decreases by 0.34 days at the cutoff. This is a substantial effect given that the average younger sibling in the sample reports 1.14 binge drinking days in the past month. While this estimate is statistically significant (95\% CI of [-0.650, 0.025]), results from similar specifications which differ in terms of outcomes or control variables are often less precise. However, point estimates are consistently negative and moderately sized. Further, our preferred estimate is well into the left tail of a distribution of placebo discontinuities estimated at older sibling ages that are close, but not equal to, 21 years.

We view our results as suggestive evidence that the causal relationship in alcohol consumption between siblings in this age range is negative. While this is counterintuitive, a large literature has established that a series of negative outcomes spike at the MLDA (e.g., Carpenter and Dobkin, 2009; Carrell et al., 2011; Lindo et al., 2013; Carpenter and Dobkin, 2015, 2017; Chalfin et al., forthcoming) and it is plausible that younger siblings update their beliefs about the costs of alcohol consumption after observing their older siblings experience these negative consequences. Unfortunately, direct tests for this mechanism are not possible due to data constraints, but we do provide several pieces of evidence supporting a true negative effect.

First, we show that the negative spillover effects and the first stage effect (discontinuity 
in older sibling's own alcohol consumption when they turn 21) are concentrated in similar subgroups of sibling-pairs (those with higher socio-economic status, non-Black and non-Hispanic race/ethnicity, or a male older sibling). Following Angrist et al. (2022), we argue that this provides evidence in favor of the exclusion restriction since it is unlikely that any other pathway from older sibling legal drinking status to younger sibling drinking behavior would exhibit this same variation across subgroups. We also show that negative effects are concentrated among same-gender sibling pairs, who we assume spend more time together (an assumption supported in the time-use literature (Dunifon et al., 2017)) and are therefore more exposed to each other's behavior.

Next, we demonstrate that our estimates are especially negative for measures of excessive consumption (binge drinking). Prior work suggests that negative effects of alcohol consumption experienced at the MLDA are driven by these types of consumption (Carpenter et al., 2016), and it is reasonable to expect that any spillover effects would be most apparent on this margin as well.

Finally, we show that these negative spillover effects do not occur in the other direction-i.e., older sibling consumption does not decrease when a younger sibling turns 21 . This can be seen as a falsification test for the proposed mechanism since an older sibling is less likely to learn from a younger sibling's alcohol consumption. Point estimates in this sample are close to zero and much more likely to be positive.

Our estimates are also almost always precise enough to rule out the relatively large positive effects reported in prior work on peer effects in alcohol consumption more generally. Notably, we compare our estimates to those from Eisenberg et al. (2014) (henceforth EGW) since they utilize what is arguably the gold-standard research design (randomized college roommates) in the literature on peer effects in alcohol consumption, and their estimates are smaller than nearly all other estimates in the related literature. ${ }^{4}$ Among 64 total specifications which can be compared to EGW, 59 confidence intervals (95\%) exclude the EGW point estimate. ${ }^{5}$

We address three specific concerns which may threaten our interpretation of these results. First, having an older sibling who can legally purchase alcohol may make it easier for the younger sibling to obtain it. However, this access effect would imply that our negative estimates are too high. Second, parents may prevent positive spillover effects when the older sibling turns 21 by monitoring younger siblings more closely, which would bias our results downwards. We are

\footnotetext{
${ }^{4}$ Notably Gaviria and Raphael (2001), Duncan et al. (2005), Lundborg (2006), Fletcher (2012), Guo et al. (2015), and Altonji et al. (2016) report similar or larger peer effects in their preferred specifications.

${ }^{5} \mathrm{EGW}$ 's comparable result is that being assigned a roommate who binge drank in the period immediately move-in leads to a $19 \%$ increase in the probability of any binge drinking by the respondent roughly 8 months later.
} 
able to provide evidence against this concern using survey questions on parenting behaviors. Third, it is possible that younger siblings are not sufficiently aware of the alcohol consumption of their older siblings despite living in the same household. This might occur if the older sibling is temporarily away at college or if the siblings do not spend much time together for some other reason. To address the former concern, we show that many older siblings in our sample are not enrolled in school and that negative spillover effects are concentrated in this group. To address the latter, we use the American Time Use Survey (ATUS) to demonstrate that siblings similar to those in our sample spend substantial amounts of time together.

We make two main contributions to the literature. First, we provide what we believe to be the first quasi-experimental estimates of sibling spillovers in alcohol consumption. Despite the importance of siblings and the strong correlation in alcohol consumption between siblings (e.g., Duncan et al., 2001; Fagan and Najman, 2005; Trim et al., 2006; Van Der Vorst et al., 2007; Whiteman et al., 2013), prior studies on spillovers in alcohol consumption have focused on non-sibling peer groups (e.g., schoolmates (Argys and Rees, 2008), roommates (Duncan et al., 2005; Eisenberg et al., 2014; Guo et al., 2015), or spouses (Fletcher and Marksteiner, 2017)), or relied on much stronger identification assumptions (Altonji et al., 2016). By exploiting an exogenous shock in older sibling consumption, we provide causal estimates of sibling spillover effects and contribute to the literature on alcohol consumption spillovers between siblings. Our results suggest that, at least in the age groups that we study, contemporaneous correlations in sibling alcohol consumption are not contagion effects. This is important as it implies that policymakers and parents should not expect that interventions aimed at decreasing the alcohol consumption of adolescents would have beneficial spillovers on their siblings.

Second, we add to a limited number of studies which provide quasi-experimental estimates of contagion effects in alcohol consumption more generally (i.e., in any peer group) without assumptions about unobservable peer characteristics. Since estimates in Argys and Rees (2008) and Eisenberg et al. (2014) are only directly interpretable as the effect of exposure to a peer (contextual effects), they rely on controls for other peer characteristics to isolate contagion effects. We exploit variation in peer behavior directly, and do not require these additional assumptions. The most similar work to ours in this respect is Fletcher and Marksteiner (2017), who estimate contagion effects of alcohol consumption with a different identification strategy (randomized assignment to an alcohol cessation program) in a very different population (adult spouses in which one spouse is a heavy drinker). To the extent peer effects operate similarly among classmates, roommates, and siblings, our results suggestion caution in interpreting existing peer effect estimates based on quasi-random assignment to peer groups as contagion effects. 


\section{Data}

The NLSY97 is a longitudinal survey of 8,984 American youths who were between the ages of 12 and 17 at the time of the first wave of the survey in 1997 (Bureau of Labor Statistics, 2019). Survey Waves are annual from 1997-2011, and biennial beginning in 2013. Designed and administered by the Bureau of Labor Statistics, the NLSY97 includes a wide variety of questions related to family processes, education, employment, health, and family formation, among other topics.

The NLSY97 has two key features which make it uniquely suitable for our analysis. First, the survey includes detailed information on the composition of each respondent's household, including the relationship of each household member to the respondent, and the age of each household member in months. Specifically, the public use version of the NLSY97 includes the exact date of the interview along with the month of birth for the respondent and all other members of the respondent's household. This allows us to observe the age in months of the respondent and all siblings who ever co-resided with the respondent during the survey, even if those siblings are not NLSY97 respondents themselves. Second, information on the alcohol consumption of respondents is obtained in all waves.

The NLSY97 sampling process first identified a large number of households and then identified all individuals in each household who were age-eligible for the survey. Because of this, a sample of siblings who are all NSLY97 respondents is available. While this sample will not be used in our main analysis, we do use it to provide descriptive evidence of between sibling correlation in alcohol consumption in the NLSY97. ${ }^{6}$

Each wave of the NLSY97 also includes a detailed set of covariates at the respondent and household levels which are also potentially related to alcohol consumption and therefore will serve as control variables in our analysis. These include the race and gender of the respondent and siblings, educational attainment and enrollment of respondents, geography (urban/rural, census region), household size, AFQT score of the respondent, an indicator for whether or not the respondent has children, an indicator for whether the respondent worked in the past year, and dummies for the calendar month and year of the survey.

We focus on measures of the excessive alcohol consumption in our main analyses: The number of binge drinking days $(5+$ drinks $)$ in the past month, and an indicator for any binge

\footnotetext{
${ }^{6}$ Table A1 shows results from a regression of the younger sibling's past month alcohol consumption on the older sibling's past month alcohol consumption for multiple measures of consumption in a sample of sibling pairs that are both NLSY97 respondents. Households with 3 or more sibling NLSY97 respondents are excluded for simplicity and the sample is limited to individuals under the age of 23 . These results are not causally interpretable and are not directly comparable to our sample of interest. However, they show that in this sample, much like in prior literature described previously, there is a very strong correlation in alcohol consumption between siblings.
} 
drinking days in the past month. This helps make our results more comparable to the existing literature, which typically focuses on measures of binge drinking, and more policy relevant, since excessive drinking is more likely to result in the various negative outcomes that are associated with alcohol consumption. The focus on a small subset of the available outcomes also helps to reduce problems of multiple testing. However, to demonstrate robustness some analyses also use binary and count measures of drinking days (days in the past month on which any drinks were consumed) as outcomes.

For reasons that we will describe in the next section, we will primarily focus on 2,614 NLSY respondents who have only one older sibling in their household, and where the older sibling is between the ages of 19 years \& 0 months (228 months of age) and 23 years \& 0 months old (276 months of age). The younger siblings in this sample are on average 18 years (215.8 months) old, and $95.4 \%$ of them are above the age of 15 years (180 months). (See Figure A1 for the full younger sibling age distribution.) Summary statistics for both the full sample of sibling-pair-years in the data and those used in our main analyses are shown in Table 1.

Alternative samples drop either the requirement that the siblings currently live together, ${ }^{7}$ the requirement that the two siblings are the oldest two siblings, or both. Key subgroups of interest are defined based on parental educational attainment, family income, race/ethnicity (recorded in the data as "Black", "Hispanic", or "Non-Black, Non-Hispanic"), whether the siblings report the same gender, the gender of the older sibling, and whether the older sibling is enrolled in school.

NLSY97 household rosters are based on the respondent's permanent address and hence include siblings who spent most of the year away at college. ${ }^{8}$ However, we note that nearly half of the observations in our main sample come from sibling-pair years where the older sibling is not enrolled in school, that not all college students live on campus, and that many college students who do live on campus attend a school that is near their permanent address (National Center for Education Statistics, 2000). According to the National Postsecondary Student Aid Study of Undergraduates $42 \%$ of students were enrolled in public 2-year institutions in the 19992000 academic year (which are likely close-to-home community colleges), 50\% of these public 2-year students still lived at home with their families, and $27 \%$ of all postsecondary students (including students attending private or 4-year institutions) lived with their parents.

\footnotetext{
${ }^{7}$ They must have lived together during at least one NLSY97 wave in order for us to observe the sibling and the sibling's age in months.

${ }^{8}$ This is technically only the case for the 1997-2002 survey waves, but the 1997-2002 survey waves do account for $91.05 \%$ of our main sample.
} 


\section{Methods}

In this section we first explain our research design and the identification assumptions that it relies on. We then explain how we use the data and design to estimate both the reduced form effect of an older sibling's legal drinking status on the younger sibling's alcohol consumption, and the first stage effect of the older sibling's legal drinking status on their own alcohol consumption.

\subsection{Estimating sibling spillover effects}

In our main analyses, we implement a reduced form regression discontinuity design in which older sibling's legal access to alcohol (an indicator for whether or not they are at least 21 years old) acts as an instrument for the older sibling's alcohol consumption. The MLDA was first used as an exogenous source of variation in alcohol consumption in a RDD by Carpenter and Dobkin (2009) to study the effect of alcohol consumption on mortality and has since been used to study a wide range of other outcomes. ${ }^{9}$ So long as no other factors related to the outcome are changing discontinuously at the cutoff, this approach will provide causally interpretable estimates. Prior work using this design has provided convincing evidence of both a strong first stage (large, discontinuous increases in consumption at age 21) and of the credibility of the research design (e.g., establishing that observable covariates do not change discontinuously at the cutoff).

Many NLSY97 respondents have more than one older sibling and this complicates estimation of peer effects with a RDD since it is unclear how to define the running variable. To avoid these complications, we define the peer group as siblings who currently reside in the same household and consider the effect of the oldest sibling in the peer group on the second oldest sibling. This ensures that we have a large sample of sibling pairs in which we observe the information necessary to implement the RDD (older sibling age in months and younger sibling alcohol consumption) and allows us to avoid the complications involved with defining the running variable in peer groups with more than two members.

The reduced form RD is then implemented by estimating the following equation via OLS:

$$
a l c_{2 h t}=\gamma_{1} 1\left\{a g e_{1 h t} \geq 21\right\}+f\left(a g e_{1 h t}\right)+X_{2 h t}^{\prime} \gamma_{2}+X_{1 h t}^{\prime} \gamma_{3}+W_{h t}^{\prime} \gamma_{4}+\theta_{2 h}+\mu_{2 h t}
$$

where subscripts denote sibling $(2=$ younger, $1=$ older $)$, household $(\mathrm{h})$, and the survey wave

\footnotetext{
${ }^{9}$ Including criminal activity (Carpenter and Dobkin, 2015; Hansen and Waddell, 2016), crime victimization (Chalfin et al., forthcoming), morbidity (Carpenter and Dobkin, 2017), marijuana consumption (Yörük and Yörük, 2011; Crost and Guerrero, 2012; Crost and Rees, 2013; Yörük and Yörük, 2013), the consumption of other illegal drugs (Deza, 2015), risky sexual behavior (Yörük and Yörük, 2015), and mental health (Yörük and Yörük, 2012).
} 
(t), the outcome is some measure of the younger sibling's past month alcohol consumption, the reduced form effect of older sibling's legal access to alcohol on the younger sibling's consumption is estimated by $\gamma_{1}, f\left(a g e_{1 h t}\right)$ is a flexible polynomial in the running variable (e.g., older sibling age fully interacted with the cutoff dummy $1\left\{\right.$ age $\left.\left._{1 h t} \geq 21\right\}\right), X_{2 h t}$ is a vector of younger sibling covariates, $X_{1 h t}$ is a vector of older sibling covariates, $W_{h t}$ is a vector of household $h$ level covariates, and $\theta_{2 h}$ is a younger sibling fixed effect.

To construct the running variable, we use the birth month of the older sibling and the month of the relevant interview. This implies that our running variable is rounded up, and that the cutoff indicator will be mismeasured for some sibling pairs in which the older sibling is exactly 21 years (252 months) old. Following the recommendations in Dong (2015), we address this misclassification bias with a "donut RD" specification that excludes sibling pairs in which the older sibling is exactly 21 years (252 months) old. Following the existing literature on MLDAbased RDDs, the sample is limited to sibling pairs in which the older sibling is between the ages of 19 and 23 -i.e., the youngest older sibling in our sample is 19 years and 0 months old (228 months of age) and the oldest is 23 years and 0 months old (276 months of age). Standard errors are cluster robust at the younger sibling level to account for correlation in the error term among observations from the same individual.

Additional models test the sensitivity of our results in several of the dimensions mentioned above (bandwidth, correction for rounding-induced bias, inclusion of covariates, inclusion of fixed effects, and order of the running variable polynomial). We also implement the "continuitybased" RD framework suggested by Cattaneo et al. (2019), including the use of a mean-squared error optimal bandwidth from Calonico et al. (2020), a triangular kernel, and bias-corrected robust confidence intervals as described in Calonico et al. $(2014,2018)$.

The main assumption required for a causal interpretation of $\gamma_{1}$ is that no unobserved confounding factors change discontinuously at the cutoff. We support this assumption assumption by estimating models similar to equation 1 , where outcomes are predicted values from separate regressions which predict the alcohol consumption measures using a range of covariates. A second required assumption is that the running variable is not manipulated. Although this is not technically a concern in our setting (since age is not manipulable), a related problem can arise if rates of nonresponse to alcohol consumption questions change discontinuously at the cutoff. This is primarily a concern in the first stage (described in the next subsection) where an older sibling may be more willing to report alcohol consumption once they reach age 21 . We test this assumption by demonstrating visually that the density of older sibling age is smooth through the cutoff and by testing formally for a discontinuity in the density at the cutoff. Finally, 
to interpret $\gamma_{1}$ as the causal effect of older sibling alcohol consumption (as opposed to older sibling legal access), we require an exclusion restriction: the older sibling's legal access must influence younger sibling alcohol consumption only through an increase in the older sibling's consumption. We provide suggestive evidence in favor of this assumption in Sections 4.3 and 5 .

\subsection{First stage discontinuities in older sibling alcohol consumption}

We separately estimate the increase in older sibling drinking at age 21 in a similar equation (where the outcome is the alcohol consumption of the older sibling, alc $c_{1 h t}$, and younger sibling characteristics are removed from the regression). Importantly, the sibling pairs used in that analysis are not the same as those used to estimate the reduced form effect. Sibling pairs in the reduced form sample are those in which the second oldest sibling the household is a NLSY97 respondent. Sibling pairs in the first stage are those in which the oldest sibling is a NLSY97 respondent.

While we could rely on the prior literature as evidence for the strength of the first stage, estimating the first stage discontinuity ourselves is useful for two reasons. First, we are interested in the magnitude of the first stage specifically for older siblings. Since the increase in alcohol consumption at MLDAs has been shown to be heterogeneous (Ahammer et al., 2022; Carpenter et al., 2016) and 21 year olds with younger siblings likely have different characteristics than those without (e.g., families with one child likely differ from those with two or more in various dimensions), the existing literature may not directly speak to this question. Second, as explained further in Section 4.3, we will use the correlation between subgroup level first stage and reduced form estimates to provide suggestive evidence in support of the exclusion restriction.

\section{Main Results}

\subsection{Research design}

We begin by demonstrating that older sibling drinking behavior changes discontinuously at age 21. Results using count and binary measures of drinking days and binge days in the past month are shown in Table 2. Similar to results from previous work using the same identification strategy in different data, ${ }^{10}$ there is a large discontinuous increase in alcohol consumption at age 21. This effect is apparent in all models shown in Table 2. In preferred models (donut specification with a linear function of the running variable, controls, ${ }^{11}$ and individual level fixed

\footnotetext{
${ }^{10}$ See the previous section for citations.

${ }^{11}$ Month and year of the survey, the race and gender of the respondent and siblings, the age of the respondent, educational attainment and enrollment of respondents, geography (urban/rural, census region), household size, AFQT score of the respondent, an indicator for whether or not the respondent has children, and an indicator for
} 
effects), past month binge drinking and drinking days increase by 0.45 days and 1.45 days at the cutoff, respectively. Both increases are statistically significant at the $5 \%$ level. Increases on the extensive margin of consumption for binge drinking and drinking (from the same models) are $5.7 \mathrm{pp}$ and at $8.3 \mathrm{pp}$ respectively, which are also both statistically significant at the $5 \%$ level. Figure 1 plots mean values of our four outcomes among older siblings in each month-of-age bin along with fitted lines and regression coefficients from the corresponding first stage regressions.

Figure A2 graphs the distribution of the older sibling's age in months, for the first stage sample. It is possible for nonresponse to change discontinuously at the cutoff and such a response could potentially affect the interpretation of the results presented in Table 2. Figure A2 suggests that this is not occurring, given that the distribution is relatively smooth through the cutoff at 21 years of age.

In Table A2 and Figure 2 we present results which test for discontinuities in sibling pair characteristics at the cutoff that could potentially confound the causal effect of interest. We use a set of covariates ${ }^{12}$ to predict each of our four (younger sibling) alcohol consumption outcomes and then use a regression analogous to our reduced form specification to test for a discontinuity in each of those predictions at the cutoff (standard errors are calculated via bootstrap). All discontinuities are statistically indistinguishable from zero.

\subsection{Reduced form}

Table 3 shows results from equation 1, estimated in the full sample of sibling pairs who reside in the same household and are the oldest two siblings in the household, for all four measures of alcohol consumption. Focusing on the preferred model (the first column) which includes the previously defined vector of controls and individual level fixed effects, all point estimates are negative and large (e.g., younger sibling past month binge days decrease by 0.34 days or $26.9 \%$ of the mean just before the cutoff). Assuming that no unobserved confounder changes discontinuously when the older sibling turns 21 , this implies that the older siblings' increase in alcohol consumption at the cutoff has a causal negative effect on the alcohol consumption of younger siblings on this margin.

Point estimates are statistically significant for only one of the four considered outcomes in our preferred specification, suggesting that these estimates should be interpreted with caution. However, the outcome for which our results are strongest (count of binge drinking days) is also arguably the most important — as it represents a particularly risky and problematic type

\footnotetext{
whether the respondent worked in the past year.

${ }^{12}$ Specifically: age, gender of both siblings, educational enrollment, highest completed education, work status, indicators for whether the household lives in an urban area, census region dummies, AFQT score, household size, and interview month/year. (All variables refer to the younger sibling's information unless otherwise noted.)
} 
of consumption. Further, point estimates for the preferred models are negative and at least modestly sized for all outcomes in the preferred specification, and nearly all estimates in Table 3. As a percentage of the mean of the outcome just before the cutoff, coefficients in the preferred specification imply that binge drinking decreases by $9.2 \%$ at the extensive margin, while drinking (any amount) decreases by $5.9 \%$ at the intensive margin and $6.7 \%$ at the extensive margin.

Corresponding binned scatter plots for all four outcomes are shown in Figure 3. These figures include coefficients from a regression of each outcome variable on the age of the older sibling (in months, centered at 21 years old), an indicator for older sibling age $\geq 21$, and their interaction (i.e., they correspond to a specification without controls or fixed effects and therefore do not align with our preferred specifications). The figures show no significant change in the alcohol consumption of younger sibling when their older sibling turns to 21, suggesting (as also shown in Table 3) that the size and precision of our negative estimates are somewhat sensitive to specification choices.

To further strengthen our results, we perform a series of placebo tests estimating discontinuities at older sibling age values near but not equal to 21 . Specifically, for each monthly age bin up to 12 months on either side of the cutoff, we re-estimate equation 1, using the preferred donut-RD specification with a linear polynomial of the running variable, controls, and fixed effects. Results are plotted in Figure 4, with the estimate at the actual cutoff value represented by a blue vertical line. While this test cannot be used to conduct formal inference, the results are reassuring - the true estimate is in the far left tail of both placebo distributions.

\subsection{Heterogeneity}

Prior work on the MLDA has uncovered consistent patterns of heterogeneity, both in the first stage and for various negative consequences of excessive alcohol consumption. Specifically, the increase in (own) alcohol consumption at age 21 has been shown to be driven by excessive consumption among males (Carpenter et al., 2016). Increases in mortality (Carpenter and Dobkin, 2009), and to a lesser extent morbidity (Carpenter and Dobkin, 2017) are also concentrated among males, while the mortality effects are further concentrated among whites (Carpenter and Dobkin, 2009). Similarly heterogeneous sibling spillover effects in our setting would provide support for our exclusion restriction. If our results represent true causal effects of older sibling alcohol consumption we would expect our negative reduced form estimates to be concentrated in the subgroups and outcomes where the first stage is strongest.

For several subgroups of interest we can estimate both reduced form and first stage effects in our data. This allows us to ask whether there is a meaningful correlation between between 
our own first stage and reduced form estimates across subgroups. Angrist et al. (2022) show that this exercise can be formalized as an overidentification test of the null hypothesis that all across-subgroup variation in the treatment effect is driven by variation in the strength of the first stage. Results consistent with such a null hypothesis are also consistent with the exclusion restriction.

This null hypothesis is implied by a model in which the older sibling's legal drinking status $1\left\{\right.$ age $\left._{1 h} \geq 21\right\}$ influences their alcohol consumption $a c_{1 h},{ }^{13}$ this first stage effect varies by some vector of sibling-pair characteristics $S_{h}$ (dummies for various binary subgroups), and older sibling consumption then influences younger sibling consumption in the same way for all sibling-pair subgroups:

$$
\begin{gathered}
\text { alc }_{2 h}=\beta_{1} a l c_{1 h}+f\left(\text { age }_{1 h}\right)+S_{h}^{\prime} \beta_{2}+\epsilon_{2 h} \\
\text { alc }_{1 h}=\alpha_{1} 1\left\{a g e_{1 h} \geq 21\right\}+\left(S_{h}^{\prime} \cdot 1\left\{a g e_{1 h} \geq 21\right\}\right) \alpha_{2}+f\left(a g e_{1 h}\right)+S_{h}^{\prime} \alpha_{3}+\eta_{1 h}
\end{gathered}
$$

Equation 3 is the first stage in a 2 SLS specification that uses the cutoff dummy $\left(1\left\{\right.\right.$ age $_{1 h} \geq$ $21\})$ and its interactions with a vector of subgroup dummies $S_{h}$ to instrument for older sibling alcohol consumption. Since the model allows the first-stage effect to vary by these subgroups, we can define subgroup-specific first-stage effects as:

$$
\alpha\left(S_{h}\right)=\alpha_{1}+S_{h}^{\prime} \alpha_{2}
$$

Since the 2SLS estimate for $\beta_{1}$ is equal to the ratio of the reduced-form effect over the first-stage effect, it follows (using notation from our reduced form specification in Section 3.1 $\left.\left(\gamma_{1}\right)\right)$ that the subgroup-specific reduced-form effects are:

$$
\gamma_{1}\left(S_{h}\right)=\alpha\left(S_{h}\right) \beta_{1}
$$

This setup can then be used to implement an overidentification test as described by Angrist et al. (2022).

\footnotetext{
${ }^{13}$ Note that while we exclude the time $(t)$ subscript here for simplicity our subgroup level results will use the same preferred specification from Section 4.2 which includes individual level fixed effects, controls, and a linear donut RD specification.
} 
Instead of a formal test, we plot the subgroup level first stage estimates (e.g., $\widehat{E}\left[\widehat{\alpha}\left(S_{h}\right) \mid G_{h}=\right.$ 1], where $G_{h}$ is some subgroup dummy) against the subgroup level reduced form estimates $\left(\widehat{E}\left[\widehat{\gamma_{1}}\left(S_{h}\right) \mid G_{h}=1\right]\right)$ to informally inspect the relationship between the two. We estimate these subgroup level first stage and reduced form effects using the corresponding specifications described in Section 3 and Section 4 in subsamples defined by the value of $G_{h}$. We do not formally implement the overidentification test because our first stage and reduced form estimates come from separate samples.

We begin in Table 4 by re-estimating our first stage (older sibling consumption) results from section 4.1 in subgroups defined by parental education (all parents completed high school vs. one or more did not complete high school), household income $\left(<\right.$ vs. $\geq$ median of $\left.\$ 53,515^{14}\right)$, school enrollment status, gender, and race (recorded in the NLSY97 as Black vs. Hispanic vs. non-Black and non-Hispanic). Similar to prior work, we find that the increase in alcohol consumption at the MLDA is driven by males. Among males the number of binge drinking days increases by 0.59 days at the cutoff, nearly double the increase of 0.32 days among females. We additionally find that the increase is driven by families with high socioeconomic status (high parental education - an increase of 0.55 days vs. 0.32 days for the lower parental education group - and household income - an increase of just under 1 day for the high income group vs, 0.14 days among the low-income group), by non-Black and non-Hispanic older siblings (an increase of 0.66 days vs. 0.18 days for Black or Hispanic older siblings), and by older siblings who are not enrolled in school (0.53 days vs 0.38 days).

Next, in Table 5 we repeat the same exercise for our reduced form results. Alignment with the first stage heterogeneity from Table 4 is striking. Larger negative spillover effects are estimated for younger siblings that have high-SES (a decrease of 0.41 days in the high parental education group vs. 0.12 days in the low education group and a decrease of 1.1 days in the high income group vs. an increase of 0.15 days in the low income group), have male older siblings (a decrease of 0.66 days vs. a small increase in the female group), are non-Black and non-Hispanic (a decrease of 0.46 days vs. 0.25 days in the Black or Hispanic group), or have an older sibling who is not enrolled in school (a decrease of 0.67 days vs 0.16 days). ${ }^{15}$ Notably, we only observe statistically significant reduced form effects in subgroups were the first stage effects are larger (at the $10 \%$ level for the high education, high income, and Non-Black \& Non-Hispanic subgroups, at the $5 \%$ level for the older sibling not enrolled in school subgroup), and all of these significant

\footnotetext{
${ }^{14}$ Note that this median is calculated from the reduced form sample. The goal of this section is to determine whether the first stage effects are driven by the same subgroups as the reduced form effects, so we want to define the subgroups similarly in both samples. Since the reduced form sample is smaller, we prioritize balancing the low and high income subgroup sizes in that sample.

${ }^{15} \mathrm{As}$ an aside, this last result is also reassuring in light of previously mentioned concerns about older siblings that may spend large portions of the year away at school.
} 
point estimates are negative. Panel (a) of Figure 5 plots the subgroup-specific reduced form and first stage estimates against each other as described above. The plots are overlaid with a fitted values from a regression of the reduced form point estimates on the first stage point estimates. This regression does not include a constant term (as implied by equation 5).

A common concern with subgroup-level analyses in RDDs is that any given subgroup dummy is likely correlated with other covariates, so that it is unclear whether heterogeneity in the treatment effect is driven by the subgroup dummy of interest or some other covariate. One could control for these other covariates (and their interaction with the treatment), but in a $\mathrm{RDD}$ these covariates would also need to be interacted with the running variable polynomial so that this approach quickly becomes untenable without very large sample sizes. Such differences present an additional reason for the first stage and reduced form estimates to diverge and threaten the logic underlying those analyses.

To address this we follow Carril et al. (2017) and Gerardino et al. (2017) and estimate, for each subgroup dummy $G_{h}$, a propensity score for $G_{h}=1$ using a set of other observables denoted by $X_{h},{ }^{16}$ and then weight the subgroup-level regressions by the inverse of that propensity score. Specifically we estimate $P\left(G_{h}=1 \mid X_{h}\right) \equiv P\left(X_{h}\right)$ as the fitted values from a probit model (with $G_{h}$ as the outcome and $X_{h}$ as the covariates) estimated via maximum likelihood. We then rerun our subgroup level first stage and reduced estimates with the following weights:

$$
G_{h} \frac{p}{P\left(X_{h}\right)}+\left(1-G_{h}\right) \frac{1-p}{1-P\left(X_{h}\right)}
$$

where $p$ is the unconditional probability that $G_{h}=1$. Standard errors are bootstrapped to account for the uncertainty in the estimated weights.

Inverse propensity score weighted results are shown in Table A3, Table A4, and panel (b) of Figure 5. Results are broadly consistent with the unweighted results and, if anything, the relationship between the subgroup-specific first stage and reduced form estimates becomes stronger (as evidence by the larger negative slope in panel (b) of Figure 5 relative to panel (a)).

For some subgroups, the hypothesis that all variation in the treatment effect is driven by variation in the the first stage may not be reasonable. This is the case if we have a strong reason to believe that meaningful treatment effect heterogeneity exists-i.e., that the reduced form effect would be heterogeneous even if there were no heterogeneity in the first stage effect.

\footnotetext{
${ }^{16}$ Specifically, race and gender of the respondent, educational attainment and enrollment of respondents, geography (urban/rural, census region), household size, AFQT score of the respondent, an indicator for whether or not the respondent has children, an indicator for whether the respondent worked in the past year, and dummies for the calendar month and year of the survey. In the reduced form specifications we also control for the older sibling's gender. In each case we omit the $G_{h}$ that the score is estimated for from the set of controls.
} 
For example, we would expect a true negative spillover effect to be concentrated among sibling pairs who are likely to spend more time together, such as same-gender sibling pairs (Dunifon et al., 2017) or sibling-pairs where the older sibling is not enrolled in school. As shown in Table 5, this is indeed the case. Among same-gender sibling pairs, younger sibling binge drinking days decrease by 0.62 days at the cutoff (statistically significant at the $5 \%$ level), the decrease is only 0.04 days among different gender sibling pairs. We also note that the negative reduced form effects are strongest for measures of excessive alcohol consumption where the first stage effect has been concentrated in the prior literature, as shown previously in Table 3.

Taken together, we believe that these patterns of heterogeneity support an interpretation of our reduced form estimates as the causal effect of older sibling alcohol consumption. It is unlikely that a spurious result or some violation of the exclusion restriction would show up in exactly the subgroups and margins of alcohol consumption where either the first stage result is strongest or where there is a strong reason to believe siblings are more exposed to eachother.

\subsection{Comparison to prior literature}

While we believe that the negative effects we estimate are plausible, our sample sizes are relatively small and the estimates are not always statistically significantly different from zero. However, given the uniformly positive effects estimated in the related literature (e.g., Gaviria and Raphael, 2001; Duncan et al., 2005; Clark and Lohéac, 2007; Lundborg, 2006; Fletcher, 2012; Eisenberg et al., 2014; Guo et al., 2015; Altonji et al., 2016; Fletcher and Marksteiner, 2017) a null result would still constitute an important contribution.

To emphasize this, we compare our results to similar estimates from Eisenberg et al. (2014) $(\mathrm{EGW})$. We choose this study for two reasons. First, their estimates are smaller than nearly all other estimates in the related literature. Therefore, if our null results are sufficiently precise to rule out the EGW point estimate, the same is true for a series of other leading estimates in the literature. ${ }^{17}$ Second, EGW utilize what we see as the best existing identification strategy on this question: randomized assignment to college roommates. Although our main focus is on peer effects among siblings, the economic literature specific to siblings is very limited (one study, Altonji et al., 2016).

EGW's key comparable result is that being assigned a roommate who binge drank in 30 days prior to a baseline survey fielded in August of 2009 (just before the students moved in to their shared rooms) leads to a $19 \%$ increase in the probability of any binge drinking by the

\footnotetext{
${ }^{17}$ Notably Gaviria and Raphael (2001), Duncan et al. (2005), Lundborg (2006), Fletcher (2012), Guo et al. (2015), and Altonji et al. (2016) all report similar or larger peer effects of alcohol consumption in their preferred specifications.
} 
respondent in a second 30-day period roughly 8 months later. In Figure 6 we scale our preferred estimate for the same outcome by the control (immediately pre-cutoff) mean, obtaining a $95 \%$ CI of $[-27.6 \%, 9.2 \%]$ in our preferred specification and ruling out the EGW point estimate (red line) in all four specifications. ${ }^{18}$

Since we estimate the direct effect of the peer's alcohol consumption, while EGW estimate the effect of exposure to a peer who binge drank in the past, we do not view these results as contradictory. Instead, if college roommates and co-resident older siblings are similar peer influences, these estimates would imply that EGW's results are explained at least in part by roommate characteristics other than drinking behavior. As mentioned previously, this is critically important for policy. Only endogenous peer effects - those which result directly from the peer's alcohol consumption-indicate that the costs of alcohol consumption are socially multiplied.

Although the EGW treatment (a roommate who did not binge drank vs. one who did) may seem larger than the effects of the MLDA on older-sibling alcohol consumption, timing implies that the difference is small. The EGW treatment is a $100 \%$ increase in exposure to peer binge drinking measured roughly 8 months in the past, while we measure a contemporaneous spillover effect. Especially given the trajectory of alcohol consumption in this age range, it is likely that many of the "control" peers in EGW (no prior binge drinking) would have binge drank by the time the outcomes were measured 8 months later. Therefore, the contemporaneous treatment vs. control difference in peer binge drinking in the EGW sample is likely much smaller than $100 \%$.

\section{Potential Mechanisms}

\subsection{Potential mechanisms}

Why might an increase in older sibling alcohol consumption at the MLDA have negative effects on younger sibling consumption? In an influential review of the economic literature on social interactions, Manski (2000) suggests that economic peer effects can operate through one of three channels: constraints, preferences, or expectations. Here we use this taxonomy to organize a discussion of potential mechanisms for the sibling spillover effects presented in Section 4 .

In our context, there are two clear constraints on a younger sibling's alcohol consumption that could be influenced by their older sibling's legal drinking status. First, there is the potential

\footnotetext{
${ }^{18}$ Additional results discussed in Section 1, further compare the EGW point estimate to our 95\% CIs from a wide range of alternative specifications. The EGW point estimate falls outside of our 95\% CIs in nearly all of these.
} 
for an "access" effect. An older sibling's ability to legally purchase alcohol could ease the access constraint faced by the younger sibling - even if the older sibling's consumption remains unchanged. We cannot test for this effect in our data, since we do not observe how (or how easily) NLSY97 respondents obtain alcohol. However, we note that an access effect would bias our negative reduced form estimates toward zero. Second, when an older sibling's alcohol consumption (or access to alcohol) increases, parents may respond by monitoring the younger sibling more closely. We can test for such responses in the NLSY97 data, and results presented in Appendix A suggest that this does not occur.

Preferences act as a mechanism for peer effects when the utility that one person derives from a behavior depends on the behavior of their peer. Preferences are commonly hypothesized as mechanisms for positive peer effects in alcohol consumption - drinking together is more fun. It is more difficult to see how such a story could explain a negative peer effect in alcohol consumption.

Expectations are perhaps the most promising class of mechanisms in our context. A peer effect operates through expectations when there is uncertainty about the costs or benefits of some behavior, and peers can reduce that uncertainty by observing each other's experiences. Alcohol consumption is a costly behavior, and this is especially true for the types of excessive consumption that respond most strongly to the MLDA (Carpenter et al., 2016). Indeed, we know that several negative outcomes spike at the MLDA. It is reasonable to expect that adolescents are uncertain about these costs, and that they would learn about them by observing role models like older siblings.

Many of the specific negative outcomes that have been studied in the MLDA literature (e.g., mortality (Carpenter and Dobkin, 2009), hospital admissions (Carpenter and Dobkin, 2017). criminal behavior (Carpenter and Dobkin, 2015), etc.) are likely too rare to explain the negative spillover effects that we estimate. However, other less severe and more common negative outcomes also likely spike at age 21. Notably, prior work provides evidence that academic performance decreases at the MLDA (Carpenter and Dobkin, 2015; Lindo et al., 2013), and poor academic performance is an example of a more commonplace negative outcome that could drive our results. To name a few other hypothetical examples, older siblings whose risky drinking behavior increases at age 21 might get in more trouble at home (or in work or school), get less sleep, or spend lots of time lying on the couch nursing a hangover.

A second important caveat to our proposed expectations mechanism is that it relies heavily on the assumption that the younger sibling is able to observe their older sibling's behavior and its consequences. We provide three pieces of suggestive evidence for this. First, our main results focus on siblings who reside in the same household and, as discussed further in Section 6, our 
reduced form estimates attenuate when we relax this restriction. Second, in Appendix B we outline a descriptive analysis which uses data from the ATUS to demonstrate that sibling pairs similar to those in our NLSY97 sample spend substantial amounts of time together. Third, we have shown in Section 5 that the negative spillover effects are concentrated among subgroups of sibling pairs that are likely to spend more time together (same-gender sibling pairs, and sibling pairs where the older sibling is not enrolled in school).

Unfortunately, data on adolescent expectations about the relevant consequences of alcohol consumption are hard to come by. The NLSY97 and some other surveys do contain survey questions on more severe and long-term risks of alcohol consumption, such as liver disease, heart disease, and alcoholism. However, it is unlikely that a younger sibling would update their beliefs about those risks based on their older sibling's contemporaneous experiences. ${ }^{19}$ Instead, empirically testing the expectations mechanism in our context would require survey questions on expectations about smaller and more immediate costs of alcohol consumption. To our knowledge, these do not exist in a data set with sample size and information (sibling age in months) sufficient for our purposes.

However, the NLSY97 data does allow us to estimate spillover effects on older siblings when a younger sibling turns 21 . This is useful because the expectations mechanism we have proposed is unlikely to be relevant when a younger sibling turns 21 . Older siblings likely have much less uncertainty about the consequences of alcohol consumption by the time their younger siblings turn 21, and younger siblings are less likely to serve as a role model. For these reasons, this exercise can be seen as a falsification test for the proposed mechanism.

Table A5 implements this falsification test using several different specifications and outcomes. Since it is less common for sibling pairs in this age range to live together (here the younger sibling is between the ages of 19 and 23), sample sizes under our typical sample definitions are relatively small in this analysis and we also present these results with alternative samples that remove either the requirement that the siblings currently live together, the requirement that the siblings are the oldest two siblings in the household, or both. Point estimates are nearly always positive. Although the estimates are somewhat imprecise, we view this as additional suggestive evidence in support of our main results.

\footnotetext{
${ }^{19}$ Even if such risk perceptions were of interest, the NLSY97 only asks these questions in a small number of survey waves (restricting our sample size), and other potential data sources have similar issues. Notably, the National Health Interview Survey (NHIS) has few respondents under age 21 and the National Longitudinal Study of Adolescent Health (Add Health) lacks the detailed household information necessary to construct our running variable.
} 


\section{Robustness}

Our main analyses focus on sibling pairs who currently reside in the same household, are the oldest two siblings in that household, and where the older sibling is between the ages of 19 and 23. In this section, we explore the robustness of our results to different sample selection criteria and to various specification choices such as the inclusion of controls or FEs.

\subsection{Alternative samples}

Table 6 presents results that remove either the requirement that the siblings currently live together, the requirement that the siblings are the oldest two siblings in the household, or both. The first panel corresponds to Table 3, which uses our main sample. Point estimates are broadly consistent (small, negative, not always statistically significant) across these samples but are closer to zero in the alternative samples. We view this as reassuring since a true spillover effect is likely to be larger when the siblings live together (siblings who do not live together likely spend less time with each other) and when the peer is the only older sibling present (if there are multiple older siblings the behavior of any one older sibling may become less influential).

\subsection{Comparing many specifications}

We visually summarize the overall robustness of our results in a plot of 64 specifications (most of which have been presented in other parts of this paper), which vary by the inclusion of fixed effects, the inclusion of controls, the order of the running variable polynomial, and the sample, in Figure A3 and Figure A4. Each regression in Figure A3 uses an indicator for any binge drinking as the outcome, and each coefficient is scaled by the corresponding "control" mean (mean of the outcome just below the cutoff) - facilitating comparisons with the EGW point estimate of $+19 \%$. Among 64 total specifications, 58 scaled estimates are negative, though the magnitudes vary and confidence intervals usually do not rule out a null effect. Among 64 total specifications, 59 confidence intervals (95\%) exclude the EGW point estimate. Figure A4 shows similar results with the count of binge drinking days as the outcome.

One additional reassuring pattern in this figure is that the handful of outlier CIs (in both figures) which include large positive effects all include quadratic polynomials in the running variable. Visual inspection of various binscatters in this paper suggest that the relationship between the outcome and running variable is linear. Further, higher-order polynomials in RD designs are known to increase the risk of detecting spurious effects (Gelman and Imbens, 2019). 


\subsection{Fixed effects}

Figure A3 and (to a lesser extent) Figure A4 highlight that our results are somewhat sensitive to the inclusion of younger sibling FEs. Models with FEs generally have more negative point estimates and tighter confidence intervals. While the improved precision is expected, sensitivity of the point estimates to the inclusion of FEs may appear surprising given that FEs should not be necessary for identification in our research design, and that adding FEs does not change the estimation sample (as shown in, e.g., Table 3). However, as explained in detail by Miller et al. (forthcoming), FE estimates are identified only by groups that have variation in treatment (here, by younger siblings who show up in our sample at least once before their older sibling turns 21 and at least once after).

In Table A6 we demonstrate that such "switchers" make up roughly two-thirds of the corresponding regression sample used in our main analyses (siblings who live together and are the two oldest siblings in the household), and that these switchers differ meaningfully in some dimensions from the remainder of the sample ("non-switchers"). Given prior results (Table 5) showing that treatment effects in this context are heterogeneous, we take this as suggestive evidence that the sensitivity of our main results to the inclusion of FEs is driven by heterogeneity in the strength of the first stage, the treatment effect, or both. Since FEs also buy us improvements in precision, and we have no a priori reason to prefer estimates for the combined sample over the switcher sample, we consider the FE estimates to be preferred.

Table A7 shows characterstics of similar switcher and non-switcher subsets of the alternative sample that does not require the siblings to live together at the time of the sample. ${ }^{20} \mathrm{~A}$ common reason for sibling pairs in our main sample to appear only when the older sibling is under 21 (i.e., to be non-switchers) is that the older sibling moves out too soon. It is therefore not suprising that switchers make up a much larger proportion of this alternative sample (without the "same household" restriction). Reassuringly, Figure A3 and Figure A4 also demonstrate that results in this alternative sample are less sensitive to the inclusion of FEs.

\subsection{Bandwidth and estimation}

All results discussed thus far have relied on a bandwidth of 24 months (i.e., restricting the sample to sibling pairs in which the older sibling is between the ages of 19 years and 0 months and 23 years and 0 months). This follows prior literature utilizing MLDA RDDs, which nearly universally chooses this bandwidth (e.g., Carpenter and Dobkin, 2009; Deza, 2015; Hansen and Waddell, 2016; Carpenter et al., 2016).

\footnotetext{
${ }^{20}$ The sample used in the bottom panel of Table 6 and denoted as "Sample 4" in Figure A3 and Figure A4.
} 
We demonstrate the robustness of our main results to the choice of bandwidth in two ways. First, Figure 7 graphs point estimates and confidence intervals from the preferred model $^{21}$ for 36 separate bandwidths (single month increments from 12 to 48 months). Results are stable across bandwidth choices, although (expectedly) less precise as bandwidth shrinks. Second, we verify that our results persist when using the framework for estimation and inference in RDDs developed by Cattaneo et al. (2019). This approach involves local polynomial estimation of the discontinuity using a mean-squared error optimal bandwidth (Calonico et al., 2020), a triangular kernel, and bias-corrected robust confidence intervals (Calonico et al., 2014, 2018). Table A8 presents results from these specifications. Column (1) and (3) use MSE-optimal bandwidths, while column (2) and column (4) use our ad-hoc 24-month bandwidth. All columns include the MSE-optimal estimates and bias-corrected robust $95 \%$ confidence intervals where the standard errors are cluster robust at individual level. Consistent with Table 3, all coefficients are negative with moderate magnitudes. For models with individual fixed effects, the coefficients are large and statistically significant compared to models without fixed effects, a pattern also present in Table 3.

\section{Conclusions}

We focus on a population which allows for the estimation of causally interpretable contagion effects in alcohol consumption under relatively weak assumptions: sibling pairs close to the MLDA in the United States. This setting is helpful for two reasons. First, it allows us to avoid empirical problems which commonly plague attempts to estimate causal peer effects. Our research design estimates contagion effects (the effect of older sibling alcohol consumption) rather than contextual effects (the effect of exposure to a peer), avoids common shocks and the reflection problem, and focuses on a peer group which is not selected. Second, despite growing evidence on the importance of sibling influences, causally interpretable estimates of sibling spillovers in alcohol consumption are rare. While somewhat imprecise, our estimates suggest that alcohol consumption of younger siblings decreases when the older sibling gains legal access to alcohol. We are consistently able to rule out large positive effects reported in the prior literature on non-sibling peer groups.

These results have several important implications for policymakers, parents, and other stakeholders interested in reducing excessive consumption of alcohol by adolescents. First, they suggest that well-known contemporaneous correlations in sibling alcohol consumption are not

\footnotetext{
${ }^{21}$ Donut RD specification including a vector of controls, a linear polynomial in the running variable fully interacted with the cutoff dummy, and individual level fixed effects
} 
causal, at least among the types of sibling-pairs in our data. Second, our results speak indirectly to recent debates about the desirability of a lower MLDA (Carpenter and Dobkin, 2011; Wechsler and Nelson, 2010; DeJong and Blanchette, 2014). Some stakeholders have argued that a lower MLDA will help adolescents learn to consume alcohol responsibly via earlier exposure but recent empirical work (Ahammer et al., 2022) has pushed back against this claim. ${ }^{22}$ We believe that our results provide suggestive evidence for a related hypothesis - that adolescents may learn more responsible drinking behavior by observing the experiences of their older siblings. Given the substantial evidence that alcohol consumption and its harms rise substantially at the MLDA, we find it unlikely that this indirect benefit (decreased lower sibling consumption) would outweigh the direct costs of a lower MLDA (increased older sibling consumption). However, our results point to a potential strategy for other interventions that attempt to improve adolescent behavior around alcohol - foster interaction with older siblings (or other role models) who have more direct experience with the substance and its negative consequences.

Our results also emphasize the important distinction between contagion effects (interpretable as the effect of the peer's behavior) and contextual effects (interpretable as the effect of exposure to the peer). A key rationale for policy makers to understand peer effects in alcohol consumption and other costly behaviors, is the potential for the costs of those behaviors - or the benefits of interventions which successfully decrease the prevalence of the behaviors - to be socially multiplied. This will occur only if the peer effect in question is a contagion effect. Many studies on peer effects, notably the leading work on spillovers in risky health behaviors based on randomly assigned college roommates, are only directly able to identify contextual peer effects. While such studies often show that their estimates are robust to the inclusion of other peer characteristics as controls (as in, e.g., Argys and Rees, 2008; Eisenberg et al., 2014), this allows for a contagion effects interpretation only if all relevant peer characteristics are observed and controlled for. Our work is unique in its ability to isolate contagion effects without any additional identification assumptions.

Several limitations are worth mentioning. First, as in any RDD, external validity is a concern. Our results apply only to a certain peer group, adolescent siblings residing in the same household where the older sibling is near the MLDA. However, our results are less limited in this way than a typical MLDA-based RDD, given that the running variable and the outcome are taken from different individuals (ages range from 12-20 years for younger siblings in our sample whose older sibling is within one month of the cutoff). Second, an older sibling's legal

\footnotetext{
${ }^{22}$ Specifically, Ahammer et al. (2022) shows that the spike in alcohol consumption at the MLDA is actually larger in a lower-MLDA setting (Austria, where the MLDA is 16 years) and provides additional evidence which suggests that obtaining legal access actually makes adolescents perceive excessive consumption as less risky.
} 
drinking status could potentially affect younger sibling consumption indirectly, e.g., via parental responses or access effects. However, one key set of confounders (parental responses) are, to some extent, ruled out based on observable information in the data, and another (access effects) are likely to bias our results towards zero.

An important goal for future work will be to understand the differences between the growing set of well-identified results on peer effects in alcohol consumption. The research designs used in our work, Fletcher and Marksteiner (2017), Argys and Rees (2008), and the series of papers utilizing randomly assigned college roommates (Duncan et al., 2005; Eisenberg et al., 2014; Guo et al., 2015) all differ in two key dimensions: the peer group studied and the assumptions necessary to disentangle contagion effects from contextual effects. Future work should aim to understand to what extent these two factors explain the differences in these results and to understand the nature of spillovers in alcohol consumption in more generalizable contexts. 


\section{References}

Ahammer, A., S. Bauernschuster, M. Halla, and H. Lachenmaier (2022): "Minimum legal drinking age and the social gradient in binge drinking," Journal of health economics, 81, 102571. (Cited on pages 10 and 23.)

Altmejd, A., A. Barrios-Fernández, M. Drlue, J. Goodman, M. Hurwitz, D. Kovac, C. Mulhern, C. Neilson, And J. Smith (2021): "O brother, where start thou? Sibling spillovers on college and major choice in four countries," The Quarterly Journal of Economics. (Cited on page 2.)

Altonji, J. G., S. Cattan, And I. Ware (2016): "Identifying sibling influence on teenage substance use," Journal of Human Resources, 0714-6474R1. (Cited on pages 2, 4, 5, and 16.)

Angrist, J., D. Autor, And A. Pallais (2022): "Marginal effects of merit aid for lowincome students," The Quarterly Journal of Economics, 137, 1039-1090. (Cited on pages 4 and 13.)

Argys, L. M. And D. I. ReEs (2008): "Searching for peer group effects: A test of the contagion hypothesis," The Review of Economics and Statistics, 90, 442-458. (Cited on pages $2,3,5,23$, and 24.)

Breining, S. N. (2014): "The presence of ADHD: Spillovers between siblings," Economics Letters, 124, 469-473. (Cited on page 2.)

Bureau of Labor Statistics (2019): "National Longitudinal Survey of Youth 1997 cohort, 1997-2017 (rounds 1-18)," U.S. Department of Labor. (Cited on page 6.)

Calonico, S., M. D. Cattaneo, and M. H. Farrell (2018): "On the effect of bias estimation on coverage accuracy in nonparametric inference," Journal of the American Statistical Association, 113, 767-779. (Cited on pages 9, 22, and 57.)

(2020): "Optimal bandwidth choice for robust bias-corrected inference in regression discontinuity designs," The Econometrics Journal, 23, 192-210. (Cited on pages 9, 22, and 57.)

Calonico, S., M. D. Cattaneo, and R. Titiunik (2014): "Robust nonparametric confidence intervals for regression-discontinuity designs," Econometrica, 82, 2295-2326. (Cited on pages 9,22 , and 57.)

Carpenter, C. and C. Dobkin (2009): "The effect of alcohol consumption on mortality: regression discontinuity evidence from the minimum drinking age," American Economic Journal: Applied Economics, 1, 164-182. (Cited on pages 2, 3, 8, 12, 18, and 21.)

(2011): "The minimum legal drinking age and public health," The Journal of Economic Perspectives, 25, 133-156. (Cited on page 23.)

(2015): "The minimum legal drinking age and crime," The Review of Economics and Statistics, 97, 521-524. (Cited on pages 2, 3, 8, and 18.)

(2017): "The minimum legal drinking age and morbidity in the United States," The Review of Economics and Statistics, 99, 95-104. (Cited on pages 2, 3, 8, 12, and 18.)

Carpenter, C. S., C. Dobkin, and C. Warman (2016): "The mechanisms of alcohol control," Journal of Human Resources, 51, 328-356. (Cited on pages 4, 10, 12, 18, and 21.)

Carrell, S. E., M. Hoekstra, And J. E. West (2011): "Does drinking impair college performance? Evidence from a regression discontinuity approach," Journal of Public Economics, 95, 54-62. (Cited on pages 2 and 3.) 
Carril, A., A. Cazor Katz, M. P. Gerardino, S. Litschig, and D. Pomeranz (2017): "RDDSGA: Stata module to conduct subgroup analysis for regression discontinuity designs," . (Cited on page 15.)

Cattaneo, M. D., N. Idrobo, and R. Titiunik (2019): A practical introduction to regression discontinuity designs: Foundations, Cambridge University Press. (Cited on pages 9 and 22.)

Cawley, J., E. Han, J. Kim, and E. C. Norton (2019): "Testing for family influences on obesity: The role of genetic nurture," Health economics, 28, 937-952. (Cited on page 2.)

Chalfin, A., B. Hansen, and R. Ryley (forthcoming): "The minimum legal drinking age and crime victimization," Journal of Human Resources. (Cited on pages 2, 3, and 8.)

Clark, A. E. AND Y. LohÉaC (2007): “"It wasn't me, it was them!" Social influence in risky behavior by adolescents," Journal of health economics, 26, 763-784. (Cited on page 16.)

Crost, B. And S. Guerrero (2012): "The effect of alcohol availability on marijuana use: Evidence from the minimum legal drinking age," Journal of health economics, 31, 112-121. (Cited on page 8.)

Crost, B. And D. I. Rees (2013): "The minimum legal drinking age and marijuana use: New estimates from the NLSY97," Journal of health economics, 32, 474-476. (Cited on page 8.)

Daysal, N. M., M. Simonsen, M. Trandafir, and S. Breining (2019): "Spillover effects of early-life medical interventions," The Review of Economics and Statistics, 1-46. (Cited on page 2.)

DeJong, W. And J. Blanchette (2014): "Case closed: research evidence on the positive public health impact of the age 21 minimum legal drinking age in the United States," Journal of Studies on Alcohol and Drugs, Supplement, 108-115. (Cited on page 23.)

DEzA, M. (2015): "The effects of alcohol on the consumption of hard drugs: regression discontinuity evidence from the National Longitudinal Study of Youth, 1997," Health economics, 24, 419-438. (Cited on pages 8 and 21.)

Dong, Y. (2015): "Regression discontinuity applications with rounding errors in the running variable," Journal of Applied Econometrics, 30, 422-446. (Cited on page 9.)

Duncan, G. J., J. Boisjoly, And K. M. Harris (2001): "Sibling, peer, neighbor, and schoolmate correlations as indicators of the importance of context for adolescent development," Demography, 38, 437-447. (Cited on pages 2 and 5.)

Duncan, G. J., J. Boisjoly, M. Kremer, D. M. Levy, and J. Eccles (2005): "Peer effects in drug use and sex among college students," Journal of abnormal child psychology, 33, 375-385. (Cited on pages 2, 4, 5, 16, and 24.)

Dunifon, R., P. Fomby, And K. Musick (2017): "Siblings and children's time use in the United States," Demographic Research, 37, 1611-1624. (Cited on pages 4, 16, and 43.)

EisenberG, D., E. Golberstein, and J. L. Whitlock (2014): "Peer effects on risky behaviors: New evidence from college roommate assignments," Journal of health economics, 33, 126-138. (Cited on pages 2, 4, 5, 16, 23, 24, 34, and 47.)

Fagan, A. A. And J. M. NAJMan (2005): "The relative contributions of parental and sibling substance use to adolescent tobacco, alcohol, and other drug use," Journal of Drug Issues, 35, 869-883. (Cited on pages 2 and 5.) 
Fletcher, J. And R. Marksteiner (2017): "Causal spousal health spillover effects and implications for program evaluation," American Economic Journal: Economic Policy, 9, 144-66. (Cited on pages 5, 16, and 24.)

Fletcher, J. M. (2012): "Peer influences on adolescent alcohol consumption: evidence using an instrumental variables/fixed effect approach," Journal of Population Economics, 25, 12651286. (Cited on pages 4 and 16.)

Gaviria, A. And S. Raphael (2001): "School-based peer effects and juvenile behavior," The Review of Economics and Statistics, 83, 257-268. (Cited on pages 4 and 16.)

Gelman, A. And G. Imbens (2019): "Why high-order polynomials should not be used in regression discontinuity designs," Journal of Business 83 Economic Statistics, 37, 447-456. (Cited on page 20.)

Gerardino, M. P., S. Litschig, And D. Pomeranz (2017): "Can audits backfire? Evidence from public procurement in Chile," NBER Working Papers. (Cited on page 15.)

Goodman, J., M. Hurwitz, J. Smith, and J. Fox (2015): "The relationship between siblings' college choices: Evidence from one million SAT-taking families," Economics of Education Review, 48, 75-85. (Cited on page 2.)

Guo, G., Y. Li, C. Owen, H. Wang, and G. J. Duncan (2015): "A natural experiment of peer influences on youth alcohol use," Social science research, 52, 193-207. (Cited on pages 2, $4,5,16$, and 24.)

Hansen, B. And G. R. Waddell (2016): "Legal Access to Alcohol and Criminality," Tech. rep., National Bureau of Economic Research. (Cited on pages 8 and 21.)

HARris, J. E. AND B. G. LÓPEZ-VAlCÁRCel (2008): "Asymmetric peer effects in the analysis of cigarette smoking among young people in the United States, 1992-1999," Journal of health economics, 27, 249-264. (Cited on page 2.)

Heissel, J. A. (2021): "Teen Fertility and Siblings' Outcomes Evidence of Family Spillovers Using Matched Samples," Journal of Human Resources, 56, 40-72. (Cited on page 2.)

Ho, C. Y. (2017): "Estimating sibling spillovers in health: Evidence on symptoms," Economics \& Human Biology, 27, 93-101. (Cited on page 2.)

Hofferth, S. L., S. M. Flood, M. Sobek, and D. Backman (2020): "American Time Use Survey Data Extract Builder: version 2.8 [dataset]," College Park, MD: University of Maryland and Minneapolis, MN: IPUMS, https://doi.org/10.18128/D060.V2.8. (Cited on pages 43 and 59.)

Joensen, J. S. And H. S. Nielsen (2018): "Spillovers in education choice," Journal of Public Economics, 157, 158-183. (Cited on page 2.)

Karbownik, K. AND U. ÖzeK (2019): "Setting a good example? Examining sibling spillovers in educational achievement using a regression discontinuity design," Tech. rep., National Bureau of Economic Research. (Cited on page 2.)

Lindo, J. M., I. D. Swensen, and G. R. Waddell (2013): "Alcohol and student performance: Estimating the effect of legal access," Journal of health economics, 32, 22-32. (Cited on pages 2,3 , and 18.)

LundBorg, P. (2006): "Having the wrong friends? Peer effects in adolescent substance use," Journal of health economics, 25, 214-233. (Cited on pages 4 and 16.) 
Manski, C. F. (1993): "Identification of endogenous social effects: The reflection problem," The Review of Economic Studies, 60, 531-542. (Cited on page 2.)

(2000): "Economic Analysis of Social Interactions," The Journal of Economic Perspectives, 14, 115-136. (Cited on pages 3 and 17.)

Miller, D. L., N. Shenhav, And M. Z. Grosz (forthcoming): "Selection into identification in fixed effects models, with application to Head Start," Journal of Human Resources. (Cited on page 21.)

National Center for Education Statistics (2000): "National Postsecondary Student Aid Survey: 2000 Undergraduates (NPSAS:UG)," United States Department of Education. Institute of Education Sciences, https://nces.ed.gov/surveys/npsas (accessed August 26, 2022). (Cited on page 7.)

Trim, R. S., E. Leuthe, And L. Chassin (2006): "Sibling influence on alcohol use in a young adult, high-risk sample," Journal of studies on alcohol, 67, 391-398. (Cited on pages 2 and 5.)

Van Der Vorst, H., R. C. Engels, W. Meeus, M. Deković, and J. Van Leeuwe (2007): "Similarities and bi-directional influences regarding alcohol consumption in adolescent sibling pairs," Addictive behaviors, 32, 1814-1825. (Cited on pages 2 and 5.)

Wechsler, H. And T. F. Nelson (2010): "Will increasing alcohol availability by lowering the minimum legal drinking age decrease drinking and related consequences among youths?" American journal of public health, 100, 986-992. (Cited on page 23.)

Whiteman, S. D., A. C. Jensen, And J. L. Maggs (2013): "Similarities in adolescent siblings' substance use: Testing competing pathways of influence," Journal of studies on alcohol and drugs, 74, 104-113. (Cited on pages 2 and 5.)

Wikle, J. S. And A. Hoagland (2020): "Adolescent interactions with family and emotions during interactions: Variation by family structure." Journal of Family Psychology, 34, 544. (Cited on page 43.)

YÖRÜK, B. K. AND C. E. YÖRÜK (2011): "The impact of minimum legal drinking age laws on alcohol consumption, smoking, and marijuana use: Evidence from a regression discontinuity design using exact date of birth," Journal of health economics, 30, 740-752. (Cited on page 8.)

(2013): "The impact of minimum legal drinking age laws on alcohol consumption, smoking, and marijuana use revisited," Journal of health economics, 32, 477-479. (Cited on page 8.)

YÖRÜK, C. E. AND B. YÖRÜK (2015): "Alcohol consumption and risky sexual behavior among young adults: evidence from minimum legal drinking age laws." Journal of Population Economics, 28. (Cited on page 8.)

YÖRÜK, C. E. AND B. K. YÖRÜK (2012): "The impact of drinking on psychological well-being: Evidence from minimum drinking age laws in the United States," Social Science 83 Medicine, 75, 1844-1854. (Cited on page 8.) 


\section{Figures and Tables}

Figure 1: Discontinuities in Older Sibling Alcohol Consumption

(a) Count of Drinking Days

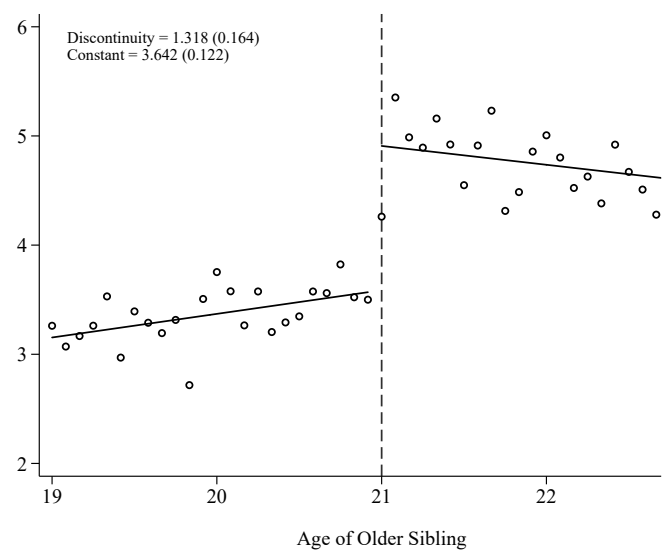

(c) Count of Binge Drinking Days

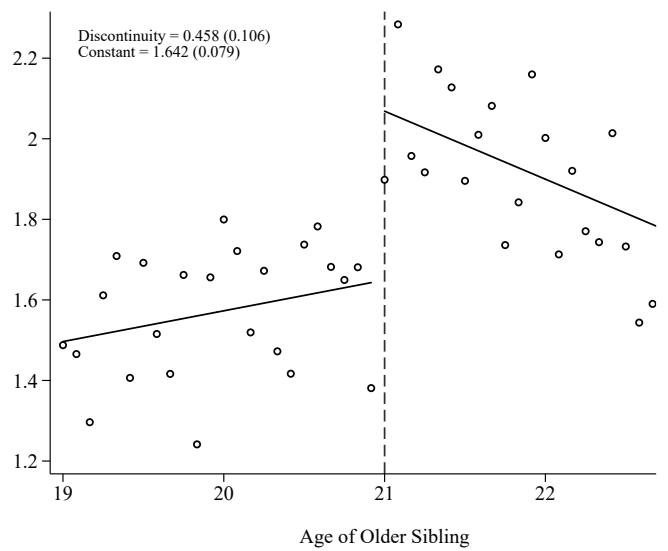

(b) Prob. of Any Drinking

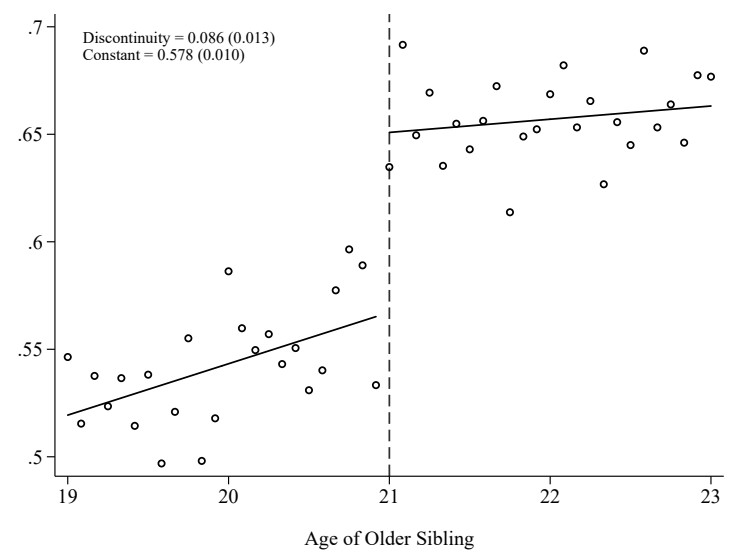

(d) Prob. of Any Binge Drinking

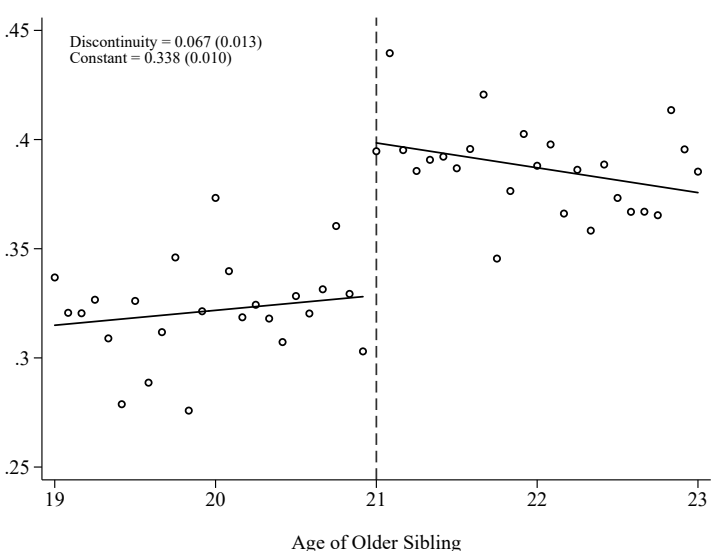

Notes: Each panel shows mean alcohol consumption in each older-sibling-age bin (in months), with linear fits estimated separately on each side of the cutoff. Point estimates and standard errors at the top left of each panel are from the corresponding OLS regressions of the relevant alcohol consumption measure on age (centered at 21), an age-21+ indicator, and their interaction (estimated with individual level data). The sample includes all NLSY97 respondents in the age range who have 1 or more younger siblings and are the oldest siblings in their household. 
Figure 2: Smoothness of Covariates at Cutoff

(a) Predicted Count of Drinking Days

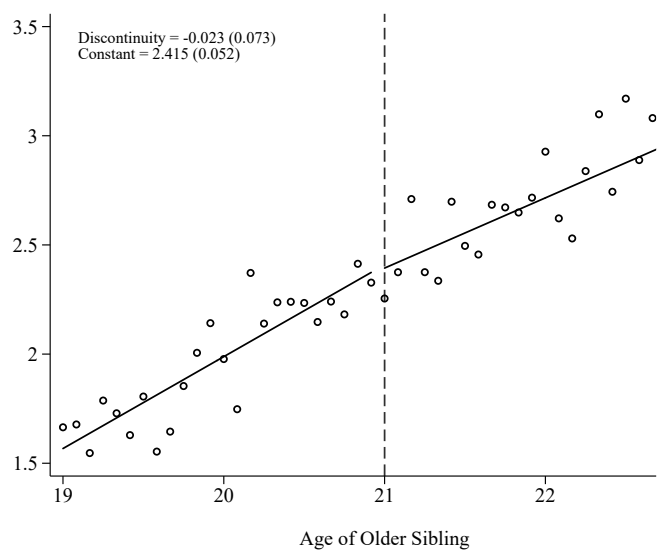

(c) Predicted Count of Binge Drinking Days

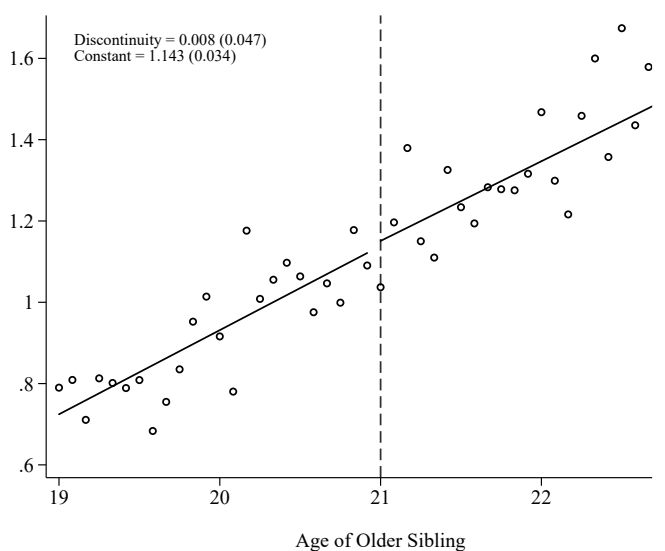

(b) Predicted Prob. of Any Drinking

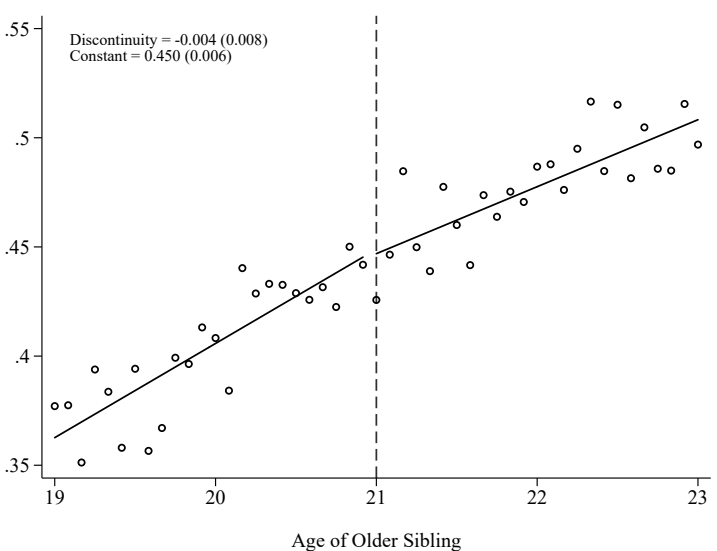

(d) Predicted Prob. of Any Binge Drinking

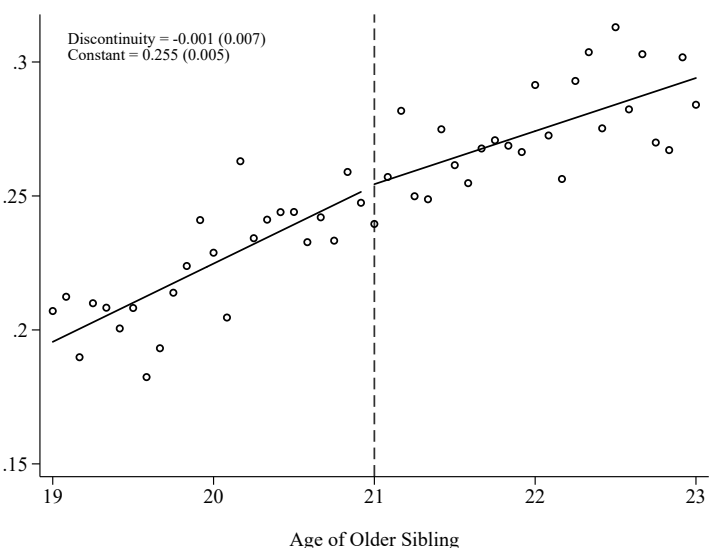

Notes: Each panel shows mean predicted alcohol consumption in each older-sibling-age bin (in months), with linear fits estimated separately on each side of the cutoff (using the binned means). Predicted alcohol consumption measures are fitted values from a regression of the corresonding alcohol consumption measure on age, gender of both siblings, educational enrollment, highest completed education, work status, indicators for whether the household lives in an urban area, census region dummies, AFQT score, household size, and interview month/year. (All variables refer to the younger sibling's information unless otherwise noted.) Point estimates and standard errors at the top left of each panel are from corresponding OLS regressions of the prediction on the running variable, the cutoff indicator, and their interaction (estimated with individual level data). Standard errors are calculated via bootstrap. The sample includes all NLSY97 respondents in the age range who are the second oldest siblings in their household. 
Figure 3: Reduced Form

(a) Count of Drinking Days

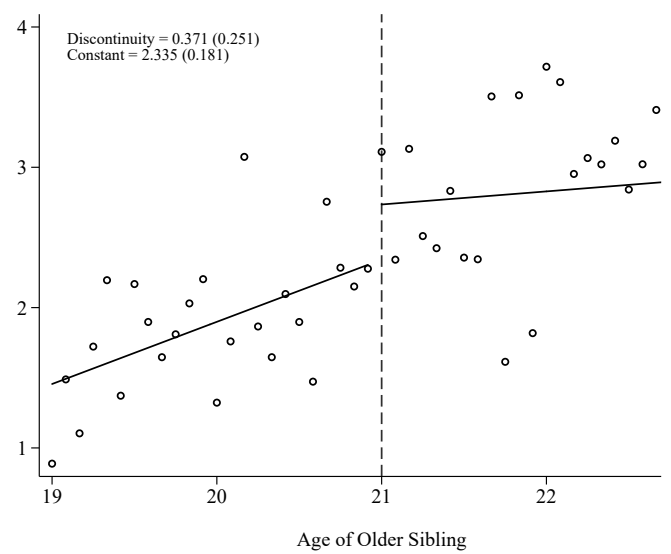

(c) Count of Binge Drinking Days

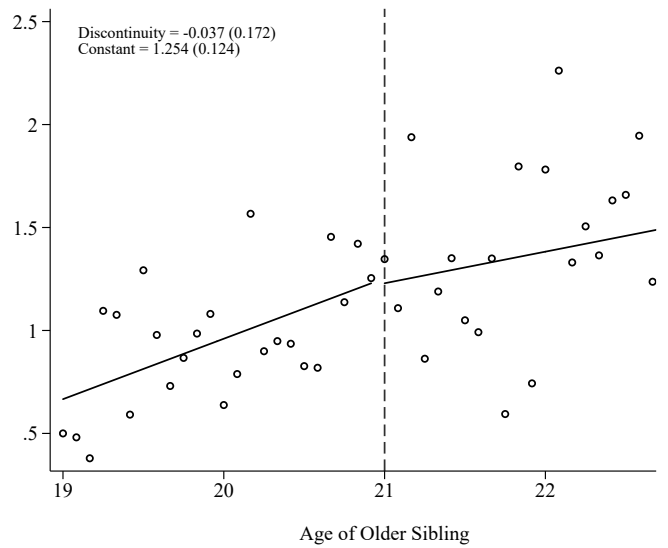

(b) Prob. of Any Drinking

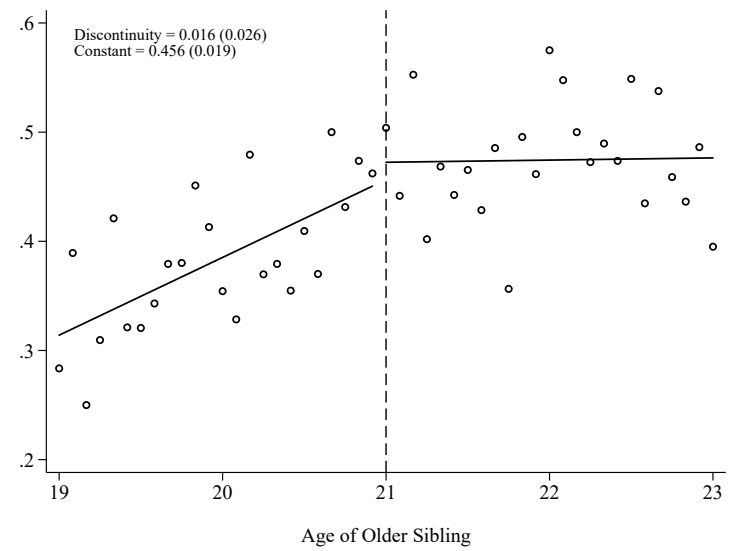

(d) Prob. of Any Binge Drinking

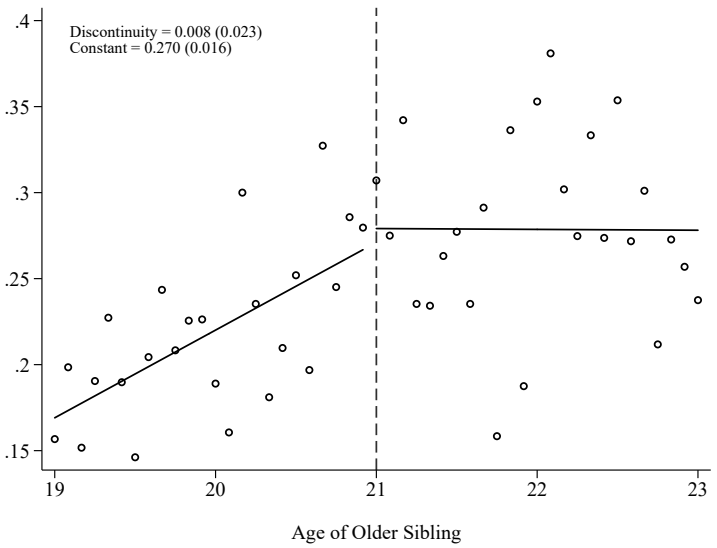

Notes: Each panel shows mean alcohol consumption in each older-sibling-age bin (in months), with linear fits estimated separately on each side of the cutoff. Point estimates and standard errors at the top left of each panel are from corresponding OLS regressions of the younger sibling's alcohol consumption on the running variable, the cutoff indicator, and their interaction (estimated with individual level data). The sample includes all NLSY97 respondents in the age range who are the second oldest siblings in their household. 
Figure 4: Placebo Discontinuities

(a) Count of Binge Drinking Days

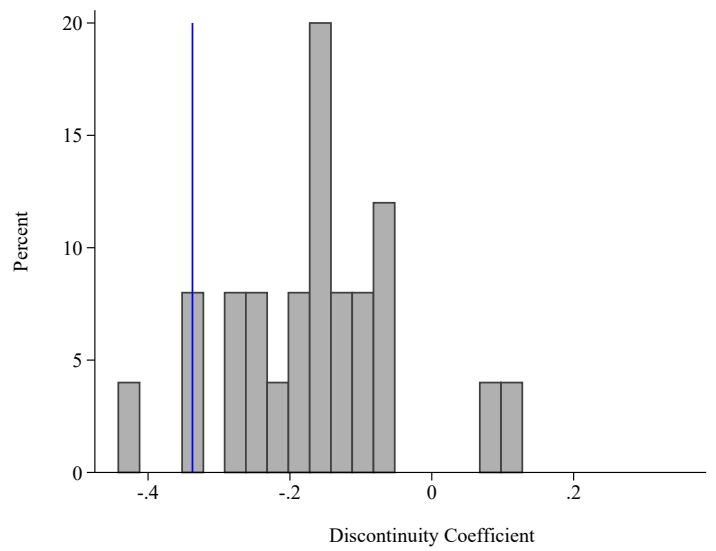

(b) Prob. of Any Binge Drinking

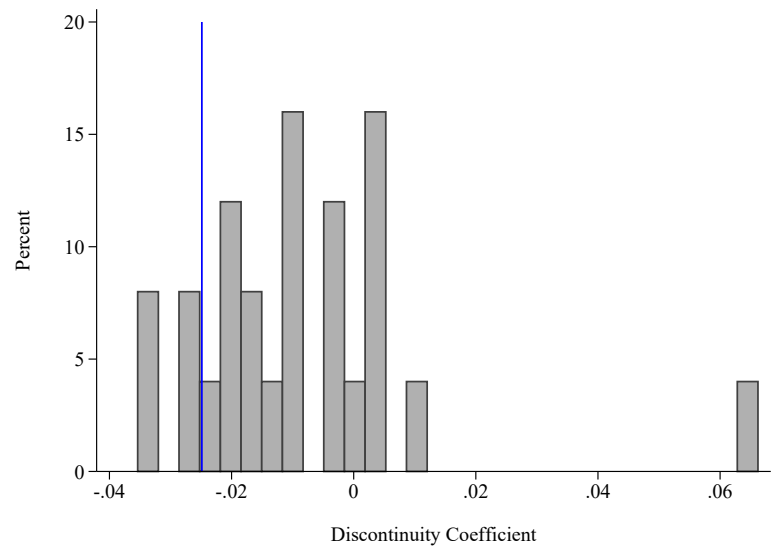

Notes: Figure shows the distribution of point estimates from a series of placebo discontinuity estimates, at running variable values near but not equal to the cutoff. Each underlying regression uses the preferred specification in Table 3 (donut, linear, controls, FE) and a different cutoff age (in months) which varies from one year below to one year above age 21. Actual estimate is shown with a vertical blue line. 
Figure 5: First Stage Effect vs Reduced Form Effet, Count of Binge Drinking Days

(a) Unweighted

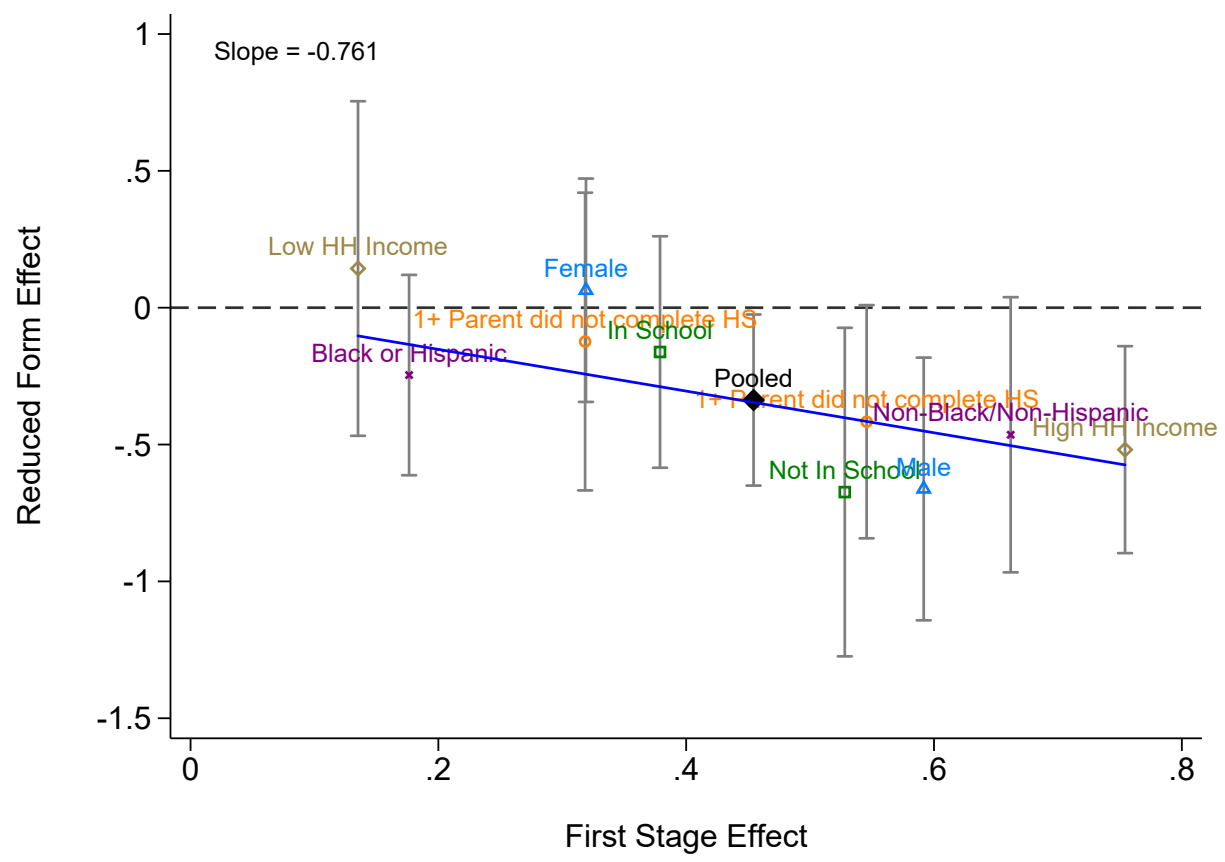

(b) Inverse Propensity Score Weighted

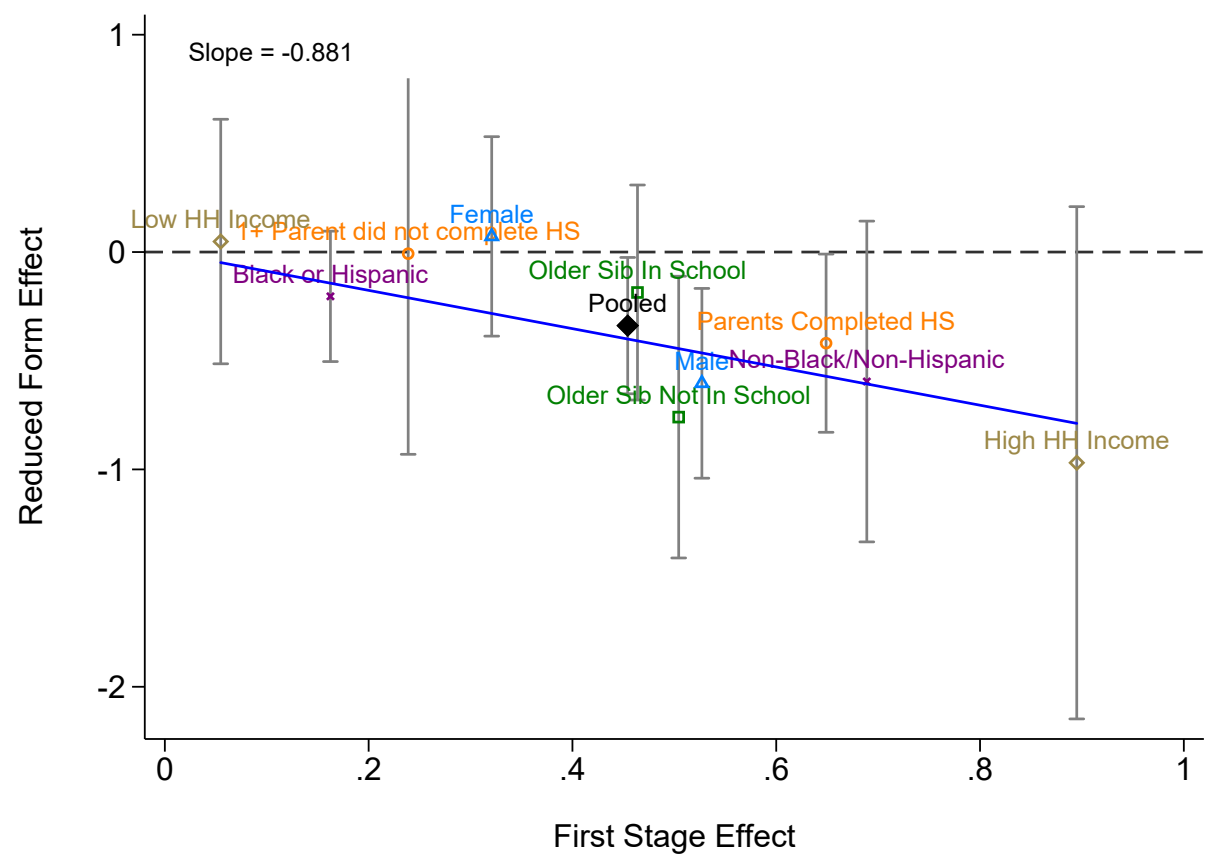

Notes: Panel (a) plots the subgroup-level first stage effects (estimates from Table 4) against the reduced form effects for the same subgroups (estimates from Table 5). Panel (b) repeats this for the inverse propensity score weighted subgroup level estimates from Table A3 and Table A4. The "pooled" estimate in both plots is from the preferred specification in the full samples (Table 2 and Table 3). Whiskers mark $95 \%$ confidence intervals. 
Figure 6: Comparison with Eisenberg et al. (2014)

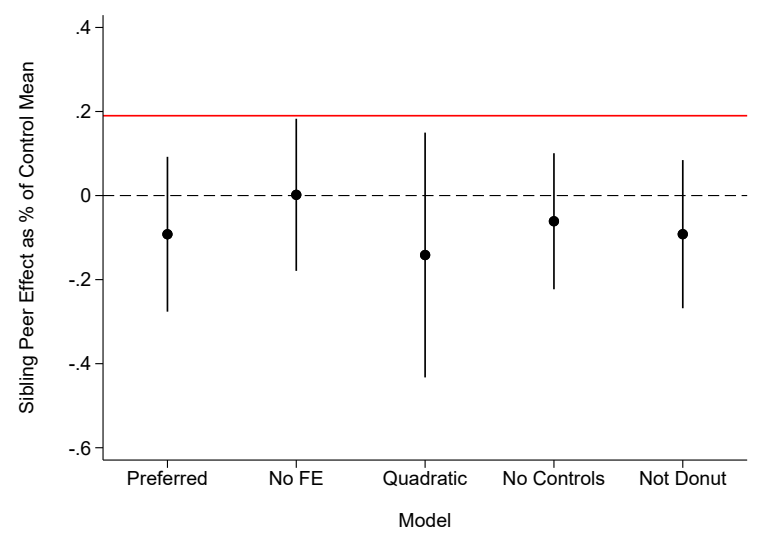

Notes: Figure shows point estimates and confidence intervals from various specifications in Table 3 alongside the main estimate from EGW (red line). The outcome in each regression (including EGW's) is an indicator for any binge drinking days in the past month. 
Figure 7: Robustness to Different Bandwidths

(a) Count of Binge Drinking Days

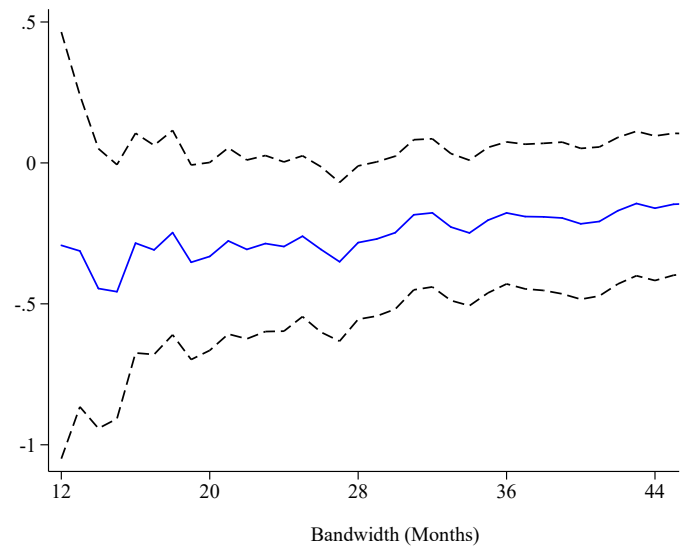

(b) Prob. of Any Binge Drinking

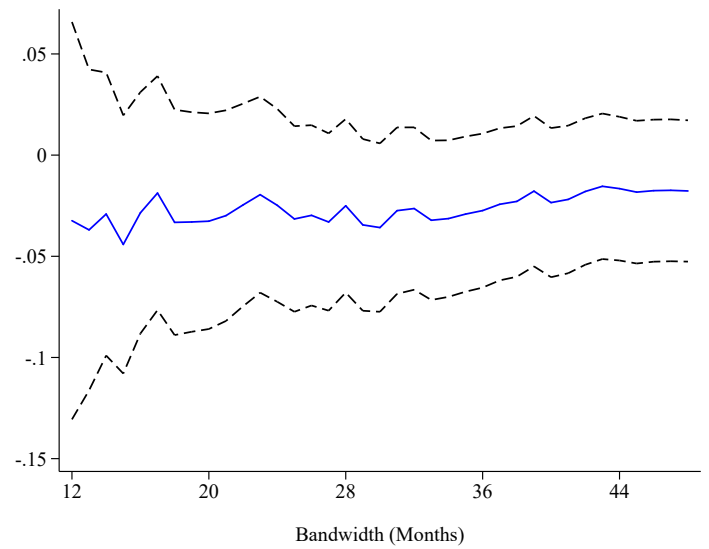

Notes: Figure shows point estimates and confidence intervals from the preferred specification in Table 3 (donut, linear, controls, FE) estimated with different bandwidths (in months). 
Table 1: NLSY97 Sample Summary Statistics

\begin{tabular}{|c|c|c|}
\hline & $\begin{array}{c}\text { Full Sample } \\
\text { mean/sd }\end{array}$ & $\begin{array}{c}\text { RDD Sample } \\
\text { mean/sd }\end{array}$ \\
\hline \multicolumn{3}{|c|}{ Younger Sibling's Past Month Drinking: } \\
\hline Drinking Days & $\begin{array}{c}2.41 \\
(4.98)\end{array}$ & $\begin{array}{c}2.31 \\
(4.76)\end{array}$ \\
\hline Any Drinking Days & $\begin{array}{c}0.41 \\
(0.49)\end{array}$ & $\begin{array}{c}0.42 \\
(0.49)\end{array}$ \\
\hline Binge Days & $\begin{array}{c}1.02 \\
(3.03)\end{array}$ & $\begin{array}{c}1.14 \\
(3.25)\end{array}$ \\
\hline Any Binge Days & $\begin{array}{c}0.23 \\
(0.42)\end{array}$ & $\begin{array}{c}0.24 \\
(0.43)\end{array}$ \\
\hline \multicolumn{3}{|l|}{ Younger Sibling's Characteristics: } \\
\hline Age & $\begin{array}{l}18.72 \\
(3.97)\end{array}$ & $\begin{array}{l}17.99 \\
(1.72)\end{array}$ \\
\hline Female & $\begin{array}{c}0.47 \\
(0.50)\end{array}$ & $\begin{array}{c}0.48 \\
(0.50)\end{array}$ \\
\hline Race: Black & $\begin{array}{c}0.28 \\
(0.45)\end{array}$ & $\begin{array}{c}0.26 \\
(0.44)\end{array}$ \\
\hline Race: Hispanic & $\begin{array}{c}0.26 \\
(0.44)\end{array}$ & $\begin{array}{c}0.24 \\
(0.43)\end{array}$ \\
\hline In High School & $\begin{array}{c}0.53 \\
(0.50)\end{array}$ & $\begin{array}{c}0.55 \\
(0.50)\end{array}$ \\
\hline In College & $\begin{array}{c}0.15 \\
(0.35)\end{array}$ & $\begin{array}{c}0.20 \\
(0.40)\end{array}$ \\
\hline Urban & $\begin{array}{c}0.78 \\
(0.41)\end{array}$ & $\begin{array}{c}0.77 \\
(0.42)\end{array}$ \\
\hline Worked Past Yr & $\begin{array}{c}0.66 \\
(0.47)\end{array}$ & $\begin{array}{c}0.71 \\
(0.46)\end{array}$ \\
\hline Household Income & $\begin{array}{l}\$ 63,484.53 \\
(58,841.17)\end{array}$ & $\begin{array}{l}\$ 61,559.45 \\
(55,247.96)\end{array}$ \\
\hline AFQT score & $\begin{array}{c}42,842.18 \\
(28,720.84)\end{array}$ & $\begin{array}{c}44,616.99 \\
(29,150.67)\end{array}$ \\
\hline \multicolumn{3}{|l|}{ Older Sibling's Characteristics: } \\
\hline Age & $\begin{array}{l}22.15 \\
(5.29)\end{array}$ & $\begin{array}{l}20.87 \\
(1.17)\end{array}$ \\
\hline Female & $\begin{array}{c}0.47 \\
(0.50)\end{array}$ & $\begin{array}{c}0.47 \\
(0.50)\end{array}$ \\
\hline Worked Past Yr & $\begin{array}{c}0.38 \\
(0.49)\end{array}$ & $\begin{array}{c}0.39 \\
(0.49)\end{array}$ \\
\hline Currently Enrolled In School & $\begin{array}{c}0.53 \\
(0.50)\end{array}$ & $\begin{array}{c}0.50 \\
(0.50)\end{array}$ \\
\hline $\mathrm{N}$ & 15,230 & 5,702 \\
\hline
\end{tabular}

Notes: The full sample consists of all NLSY respondents with older siblings living in the same household. Our analysis sample ("RDD") consists of co-resident siblings who are the oldest two siblings in the household, where the younger sibling is a NLSY97 respondent and the older sibling is between the ages of 19 and 23 . 
Table 2: Discontinuities in Older Sibling Alcohol Consumption

\begin{tabular}{|c|c|c|c|c|c|}
\hline & \multicolumn{5}{|c|}{ Count of Drinking Days } \\
\hline & (1) & $(2)$ & $(3)$ & $(4)$ & $(5)$ \\
\hline \multirow[t]{2}{*}{ Age $21+$} & $1.447^{* * *}$ & $1.579^{* * *}$ & $1.831^{* * *}$ & $1.339^{* * *}$ & $1.329^{* * *}$ \\
\hline & $(0.152)$ & $(0.169)$ & $(0.241)$ & $(0.133)$ & $(0.146)$ \\
\hline Control Mean & 3.642 & 3.642 & 3.642 & 3.642 & 3.642 \\
\hline \multirow[t]{2}{*}{ Observations } & 16,682 & 16,682 & 16,682 & 21,376 & 17,049 \\
\hline & \multicolumn{5}{|c|}{ Any Drinking Days } \\
\hline \multirow[t]{2}{*}{ Age $21+$} & $0.083^{* * *}$ & $0.089^{* * *}$ & $0.104^{* * *}$ & $0.083^{* * *}$ & $0.079^{* * *}$ \\
\hline & $(0.013)$ & $(0.013)$ & $(0.019)$ & $(0.011)$ & $(0.012)$ \\
\hline Control Mean & 0.578 & 0.578 & 0.578 & 0.578 & 0.578 \\
\hline \multirow[t]{2}{*}{ Observations } & 16,682 & 16,682 & 16,682 & 21,376 & 17,049 \\
\hline & \multicolumn{5}{|c|}{ Count of Binge Drinking Days } \\
\hline \multirow[t]{2}{*}{ Age $21+$} & $0.454^{* * *}$ & $0.582^{* * *}$ & $0.678^{* * *}$ & $0.404^{* * *}$ & $0.405^{* * *}$ \\
\hline & $(0.100)$ & $(0.111)$ & $(0.161)$ & $(0.089)$ & $(0.095)$ \\
\hline Control Mean & 1.642 & 1.642 & 1.642 & 1.642 & 1.642 \\
\hline \multirow[t]{2}{*}{ Observations } & 16,601 & 16,601 & 16,601 & 21,268 & 16,964 \\
\hline & \multicolumn{5}{|c|}{ Any Binge Drinking Days } \\
\hline \multirow[t]{2}{*}{ Age $21+$} & $0.056^{* * *}$ & $0.067^{* * *}$ & $0.073^{* * *}$ & $0.058^{* * *}$ & $0.050^{* * *}$ \\
\hline & $(0.012)$ & $(0.013)$ & $(0.020)$ & $(0.011)$ & $(0.012)$ \\
\hline Control Mean & 0.338 & 0.338 & 0.338 & 0.338 & 0.338 \\
\hline Observations & 16,601 & 16,601 & 16,601 & 21,268 & 16,964 \\
\hline $\mathrm{FE}$ & $\mathrm{X}$ & & $\mathrm{X}$ & $\mathrm{X}$ & $\mathrm{X}$ \\
\hline Quadratic & & & $\mathrm{X}$ & & \\
\hline Controls & $\mathrm{X}$ & $\mathrm{X}$ & $\mathrm{X}$ & & $\mathrm{X}$ \\
\hline Donut & $\mathrm{X}$ & $\mathrm{X}$ & $\mathrm{X}$ & $\mathrm{X}$ & \\
\hline
\end{tabular}

Notes: Controls include the month and year of the survey, the gender and age of the respondent and siblings, race of respondents, educational attainment and enrollment of respondents, geography (urban/rural, census region), household size, AFQT score of the respondent, an indicator for whether or not the respondent has children, and an indicator for whether the respondent worked in the past year. All models are estimated in a sample of NLSY97 respondents who are the oldest siblings currently residing in their household who are between the ages of 19 and 23. All models include cluster robust standard errors at individual level. Age is centered at 21 years. +, $*$, **, and $* * *$ denote statistical significance at the $10 \%, 5 \%, 1 \%$, and $0.1 \%$ levels, respectively. 
Table 3: Reduced Form

\begin{tabular}{|c|c|c|c|c|c|}
\hline & \multicolumn{5}{|c|}{ Count of Drinking Days } \\
\hline & (1) & $(2)$ & $(3)$ & $(4)$ & $(5)$ \\
\hline \multirow{2}{*}{ Sibling $21+$} & -0.139 & 0.101 & -0.301 & 0.156 & -0.061 \\
\hline & $(0.250)$ & $(0.249)$ & $(0.431)$ & $(0.229)$ & $(0.242)$ \\
\hline Control Mean & 2.335 & 2.335 & 2.335 & 2.335 & 2.335 \\
\hline \multirow[t]{2}{*}{ Observations } & 4,282 & 4,282 & 4,282 & 5,527 & 4,373 \\
\hline & \multicolumn{5}{|c|}{ Any Drinking Days } \\
\hline \multirow[t]{2}{*}{ Sibling $21+$} & -0.031 & -0.009 & -0.060 & 0.004 & -0.035 \\
\hline & $(0.028)$ & $(0.028)$ & $(0.046)$ & $(0.025)$ & $(0.027)$ \\
\hline Control Mean & 0.456 & 0.456 & 0.456 & 0.456 & 0.456 \\
\hline \multirow[t]{2}{*}{ Observations } & 4,282 & 4,282 & 4,282 & 5,527 & 4,373 \\
\hline & \multicolumn{5}{|c|}{ Count of Binge Drinking Days } \\
\hline \multirow[t]{2}{*}{ Sibling 21+ } & $-0.338^{*}$ & -0.175 & -0.377 & -0.195 & $-0.298^{+}$ \\
\hline & $(0.160)$ & $(0.169)$ & $(0.268)$ & $(0.161)$ & $(0.154)$ \\
\hline Control Mean & 1.254 & 1.254 & 1.254 & 1.254 & 1.254 \\
\hline \multirow[t]{2}{*}{ Observations } & 4,278 & 4,278 & 4,278 & 5,521 & 4,369 \\
\hline & \multicolumn{5}{|c|}{ Any Binge Drinking Days } \\
\hline \multirow[t]{2}{*}{ Sibling 21+ } & -0.025 & 0.001 & -0.040 & -0.017 & -0.025 \\
\hline & $(0.025)$ & $(0.025)$ & $(0.040)$ & $(0.022)$ & $(0.024)$ \\
\hline Control Mean & 0.270 & 0.270 & 0.270 & 0.270 & 0.270 \\
\hline Observations & 4,278 & 4,278 & 4,278 & 5,521 & 4,369 \\
\hline $\mathrm{FE}$ & $\mathrm{X}$ & & $\mathrm{X}$ & $\mathrm{X}$ & $\mathrm{X}$ \\
\hline Quadratic & & & $\mathrm{X}$ & & \\
\hline Controls & $\mathrm{X}$ & $\mathrm{X}$ & $\mathrm{X}$ & & $\mathrm{X}$ \\
\hline Donut & $\mathrm{X}$ & $\mathrm{X}$ & $\mathrm{X}$ & $\mathrm{X}$ & \\
\hline
\end{tabular}

Notes: Controls include the month and year of the survey, the gender and age of the respondent and siblings, race of respondents, educational attainment and enrollment of respondents, geography (urban/rural, census region), household size, AFQT score of the respondent, an indicator for whether or not the respondent has children, and an indicator for whether the respondent worked in the past year. All models are estimated in a sample of NLSY97 respondents who have exactly one older sibling in their household, and where that older sibling is between the ages of 19 and 23. All models include cluster robust standard errors at individual level. Sibling age is centered at 21 years. $+,{ }^{*},{ }^{* *}$, and ${ }^{* * *}$ denote statistical significance at the $10 \%, 5 \%, 1 \%$, and $0.1 \%$ levels, respectively. 
Table 4: Discontinuities in Older Sibling Alcohol Consumption in Subgroups, Binge Days

\begin{tabular}{|c|c|c|c|c|}
\hline & \multicolumn{2}{|c|}{ Parental Education } & \multicolumn{2}{|c|}{ Household Income } \\
\hline & $<\mathrm{HS}$ & $\geq \mathrm{HS}$ & $<$ Median & $\geq$ Median \\
\hline \multirow[t]{2}{*}{ Age $21+$} & $0.315^{+}$ & $0.546^{* * *}$ & 0.141 & $0.971^{* * *}$ \\
\hline & $(0.184)$ & $(0.153)$ & $(0.146)$ & $(0.237)$ \\
\hline Control Mean & 1.120 & 1.992 & 1.527 & 1.905 \\
\hline \multirow{3}{*}{ Observations } & 3,992 & 8,085 & 8,651 & 5,009 \\
\hline & \multicolumn{2}{|c|}{ Older Sibling's School Enrollment } & \multicolumn{2}{|c|}{ Older Sibling's Sex } \\
\hline & Enrolled & Not Enrolled & Male & Female \\
\hline \multirow[t]{2}{*}{ Age $21+$} & $0.379^{*}$ & $0.528^{* * *}$ & $0.593^{* * *}$ & $0.320^{* *}$ \\
\hline & $(0.152)$ & $(0.146)$ & $(0.171)$ & $(0.108)$ \\
\hline Control Mean & 1.729 & 1.590 & 2.360 & 0.930 \\
\hline \multirow[t]{4}{*}{ Observations } & 6,560 & 10,041 & 8,127 & 8,474 \\
\hline & \multicolumn{2}{|c|}{ Race } & & \\
\hline & Black or & Non-Black \& & & \\
\hline & Hispanic & Non-Hispanic & & \\
\hline \multirow[t]{2}{*}{ Age $21+$} & 0.175 & $0.662^{* * *}$ & & \\
\hline & $(0.129)$ & $(0.148)$ & & \\
\hline Control Mean & 1.055 & 2.136 & & \\
\hline Observations & 7,206 & 9,395 & & \\
\hline
\end{tabular}

Notes: Controls include the month and year of the survey, the gender and age of the respondent and siblings, race of respondents, educational attainment and enrollment of respondents, geography (urban/rural, census region), household size, AFQT score of the respondent, an indicator for whether or not the respondent has children, and an indicator for whether the respondent worked in the past year. All models are estimated in the corresponding subgroup of a sample of NLSY97 respondents who are the oldest siblings currently residing in their household who are between the ages of 19 and 23. The median household income is $\$ 53,515$. All models include cluster robust standard errors at individual level. Age is centered at 21 years. $+,{ }^{*},{ }^{*}$, and ${ }^{* * *}$ denote statistical significance at the $10 \%, 5 \%, 1 \%$, and $0.1 \%$ levels, respectively. 
Table 5: Reduced Form in Subgroups, Binge Days

\begin{tabular}{|c|c|c|c|c|}
\hline & \multicolumn{2}{|c|}{ Parental Education } & \multicolumn{2}{|c|}{ Household Income } \\
\hline & $<\mathrm{HS}$ & $\geq \mathrm{HS}$ & $<$ Median & $\geq$ Median \\
\hline \multirow[t]{2}{*}{ Sibling 21+ } & -0.121 & $-0.417^{+}$ & 0.146 & $-1.106^{+}$ \\
\hline & $(0.277)$ & $(0.216)$ & $(0.317)$ & $(0.648)$ \\
\hline Control Mean & 1.128 & 1.477 & 0.957 & 2.362 \\
\hline \multirow{3}{*}{ Observations } & 1,045 & 2,206 & 875 & 875 \\
\hline & \multicolumn{2}{|c|}{ Older Sibling's School Enrollment } & \multicolumn{2}{|c|}{ Older Sibling's Sex } \\
\hline & Enrolled & Not Enrolled & Male & Female \\
\hline \multirow{2}{*}{ Sibling $21+$} & -0.160 & $-0.666^{*}$ & $-0.659^{* *}$ & 0.069 \\
\hline & $(0.215)$ & $(0.298)$ & $(0.244)$ & $(0.210)$ \\
\hline Control Mean & 1.259 & 1.214 & 1.344 & 1.143 \\
\hline \multirow[t]{3}{*}{ Observations } & 2,184 & 2,074 & 2,266 & 2,012 \\
\hline & \multicolumn{2}{|c|}{ Race } & \multicolumn{2}{|c|}{ Sibling Sex Composition } \\
\hline & $\begin{array}{l}\text { Black or } \\
\text { Hispanic }\end{array}$ & $\begin{array}{l}\text { Non-Black \& } \\
\text { Non-Hispanic }\end{array}$ & Same & Different \\
\hline \multirow[t]{2}{*}{ Sibling $21+$} & -0.250 & $-0.464^{+}$ & $-0.617^{* *}$ & -0.040 \\
\hline & $(0.188)$ & $(0.256)$ & $(0.233)$ & $(0.223)$ \\
\hline Control Mean & 0.903 & 1.613 & 1.348 & 1.138 \\
\hline Observations & 2,020 & 2,258 & 2,379 & 1,899 \\
\hline
\end{tabular}

Notes: Controls include the month and year of the survey, the gender and age of the respondent and siblings, race of respondents, educational attainment and enrollment of respondents, geography (urban/rural, census region), household size, AFQT score of the respondent, an indicator for whether or not the respondent has children, and an indicator for whether the respondent worked in the past year. All models are estimated in the corresponding subgroup of a sample of NLSY97 respondents who have exactly one older sibling in their household, and where that older sibling is between the ages of 19 and 23 . The median household income is $\$ 53,515$ in this sample. All models include cluster robust standard errors at individual level. Sibling age is centered at 21 years. $+,{ }^{*}, * *$, and $* * *$ denote statistical significance at the $10 \%, 5 \%, 1 \%$, and $0.1 \%$ levels, respectively. 
Table 6: Alternative Samples

\begin{tabular}{|c|c|c|c|c|}
\hline & $\begin{array}{c}\text { Drinking } \\
\text { Days }\end{array}$ & $\begin{array}{c}\text { Any } \\
\text { Drinking Days }\end{array}$ & $\begin{array}{c}\text { Binge } \\
\text { Drinking Days }\end{array}$ & $\begin{array}{c}\text { Any Binge } \\
\text { Drinking Days }\end{array}$ \\
\hline & \multicolumn{4}{|c|}{ Two Oldest Siblings Living in the Same Household } \\
\hline \multirow[t]{2}{*}{ Sibling 21+ } & -0.139 & -0.031 & $-0.338^{*}$ & -0.025 \\
\hline & $(0.250)$ & $(0.028)$ & $(0.160)$ & $(0.025)$ \\
\hline Control Mean & 2.335 & 0.456 & 1.254 & 0.270 \\
\hline \multirow[t]{2}{*}{ Observations } & 4,282 & 4,282 & 4,278 & 4,278 \\
\hline & \multicolumn{4}{|c|}{ Two Siblings Living in the Same Household } \\
\hline \multirow[t]{2}{*}{ Sibling $21+$} & 0.025 & -0.025 & $-0.253^{+}$ & -0.024 \\
\hline & $(0.229)$ & $(0.026)$ & $(0.147)$ & $(0.023)$ \\
\hline Control Mean & 2.305 & 0.447 & 1.215 & 0.267 \\
\hline \multirow[t]{2}{*}{ Observations } & 5,100 & 5,100 & 5,094 & 5,094 \\
\hline & \multicolumn{4}{|c|}{ Two Oldest Siblings } \\
\hline \multirow[t]{2}{*}{ Sibling $21+$} & -0.230 & -0.016 & $-0.206^{+}$ & -0.026 \\
\hline & $(0.186)$ & $(0.020)$ & $(0.121)$ & $(0.018)$ \\
\hline Control Mean & 2.472 & 0.472 & 1.271 & 0.290 \\
\hline \multirow[t]{2}{*}{ Observations } & 6,988 & 6,988 & 6,975 & 6,975 \\
\hline & \multicolumn{4}{|c|}{ Two Siblings } \\
\hline \multirow[t]{2}{*}{ Sibling 21+ } & -0.079 & -0.025 & -0.109 & -0.021 \\
\hline & $(0.162)$ & $(0.016)$ & $(0.101)$ & $(0.015)$ \\
\hline Control Mean & 2.384 & 0.456 & 1.184 & 0.274 \\
\hline Observations & 9,975 & 9,975 & 9,958 & 9,958 \\
\hline
\end{tabular}

Notes: The first panel is estimated in a sample of NLSY97 respondents who have exactly one older sibling in their household, and where that older sibling is between the ages of 19 and 23. The second panel is estimated in a sample of NLSY97 respondents who are the second oldest siblings, where their older sibling is between the ages of 19 and 23, and the older sibling may not currently reside in the same household as the respondent. The third panel is estimated in a sample of NLSY97 respondents who have one or more older siblings in their household where the closest older sibling to the respondent is between the ages of 19 and 23 . The last panel is estimated in a sample of NLSY respondents who have one or more older siblings where the closest older sibling to the respondent is between the ages of 19 and 23, and the closest older sibling may not currently reside in the same household as the respondent. Controls include the month and year of the survey, the gender and age of the respondent and siblings, race of respondents, educational attainment and enrollment of respondents, geography (urban/rural, census region), household size, AFQT score of the respondent, an indicator for whether the respondent has children, and an indicator for whether the respondent worked in the past year. All models include cluster robust standard errors at individual level. Sibling age is centered at 21 years. $+, *, * *$, and $* * *$ denote statistical significance at the $10 \%, 5 \%, 1 \%$, and $0.1 \%$ levels, respectively. 


\section{Appendices}

\section{A Evidence against offsetting parental responses}

As described in section ?? parental responses are one key pathway through which the older sibling's legal access to alcohol could directly (i.e., not via an endogenous peer effect) affect the younger sibling's consumption of alcohol. The NLSY97 includes two separate questions which can provide some suggestive evidence on the role that parental responses play in explaining the results described above. First, all respondents are asked to score the degree to which they are monitored by their parents (including, if applicable, parents they live with and parents they do not live with) on a scale from 0-16, with higher scores indicating closer monitoring. Second, respondents are asked to classify their parents' parenting styles (again, including if applicable parents who do and do not live with the respondent) as either uninvolved, permissive, authoritarian, or authoritative.

In the first panel of Table A9 we present results for models similar to equation 1 with the parental monitoring score for the parents that the respondent lives with as the outcome. If the respondent lives with two parents, the outcome is their average score. In the second panel of Table A9, similar results are presented with an indicator for whether or not at least one parent was reported to be either authoritarian or authoritative.

The survey questions underlying these outcomes are asked only in survey rounds between 1997 and 2000. Luckily, a substantial portion of the sibling-pair-years that meet our sample restriction requirements are in this time period. However, some are not, and sample sizes are therefore smaller than the previously described full sample results in Table 3. Models in Table A9 are the same as those in Table 3 in order to demonstrate the robustness of the results.

In each of the 5 models for each of the three outcomes, point estimates for a discontinuity in parental behavior at the cutoff are either negative (suggesting parents become less strict or engage in less monitoring), not statistically significant, or both. In the preferred model (1) neither point estimate is economically significant. We interpret this as suggestive evidence that parental responses are not driving the observed decrease in younger sibling alcohol consumption at the cutoff.

\section{B Time use of siblings near the MLDA}

As described in section ??, a concern in our setting is that younger siblings may not be sufficiently exposed to changes in older sibling alcohol consumption that occur at the MLDA. This might be the case if, for example, siblings in this age range do not spend meaningful amounts 
of time together.

While a small literature on the shared time use of siblings does exist (e.g., Dunifon et al., 2017; Wikle and Hoagland, 2020), there does not appear to be any work on the age ranges relevant for our analysis. We therefore address this concern with a simple descriptive analysis which demonstrates that siblings at ages near the MLDA spend substantial amounts of time together - even after excluding time with parents, and especially when focusing on same-gender sibling pairs.

The ATUS is a repeated cross-sectional survey, which regularly samples a subset of Current Population Survey (CPS) respondents and solicits a detailed time-diary for one day's worth of activities (Hofferth et al., 2020). These time diaries detail the minute-level activities of respondents, including what activity was being performed, where, and with whom. Since the ATUS sample is drawn from the CPS, the two surveys can be linked so that the household structure of each ATUS respondent is observable. We use this information to select all respondents from the 2003-2019 waves of the ATUS who lived with only one older sibling who was 23 years old or younger. We then use the information on who activities were performed with to characterize the strength of these sibling relationships and provide suggestive evidence regarding the potential for younger siblings to be exposed to changes in older sibling alcohol consumption. Summary statistics for our analysis sample of 2,795 ATUS respondents are shown in Table A10.

We calculate average time spent per day with an older sibling. For comparison, we also calculate average time spent per day with friends. ${ }^{23}$ Finally, we present these means in several different subsets of activities. First, we move from all activities reported in the time-diary to activities performed while not at work or school - under the assumption that such "discretionary" time is more relevant for the behavior we are interested in. Second, we further restrict our focus to time spent not at work or school and without any parents present for the same reason. Finally, we break down this last category of discretionary and unsupervised time into the main activity groups defined by ATUS. ${ }^{24}$ Results are shown in Figure A5.

The average respondent reports spending roughly 1 hour and 50 minutes with an older sibling during their diary-day, just under one hour of which is discretionary and unsupervised time, when alcohol consumption would be most likely to occur. Since a substantial portion of the average diary-day in our sample is spent either at work, at school, or with parents (see Table A10), this is a meaningful amount of time. Moreover, the activities that siblings engage in together during this discretionary and unsupervised time (right panel of the figure) are broadly

\footnotetext{
${ }^{23}$ We consider an activity to be performed with an older sibling (or similarly, with a friend) if the so-called "who" record in the ATUS data lists at least one older sibling (or friend).

${ }^{24}$ Note that it is not possible to directly observe alcohol consumption in the ATUS.
} 
similar to the activities engaged in with friends. While it is clear that respondents spend more time with friends (especially within discretionary and supervised time), we argue that this is strong evidence that the sibling pairs we study in our main analysis are a meaningful peer group for the behavior of interest. 


\section{Appendix Figures and Tables}

Figure A1: Age Distribution of Younger Sibling

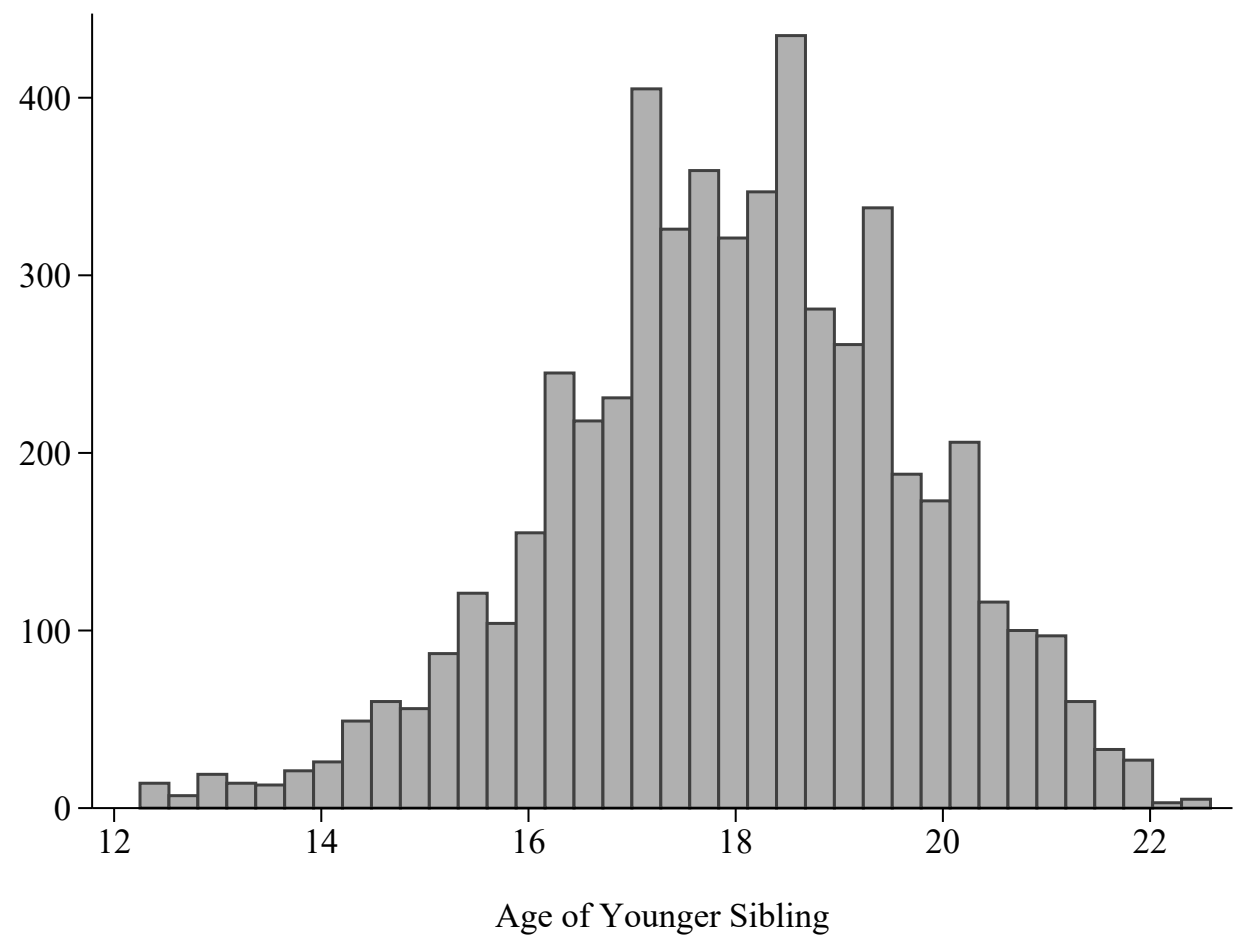

Notes: Y-axis shows the count of younger siblings in our sample with each age value (age in months of youngerd sibling). 
Figure A2: Density of Running Variable

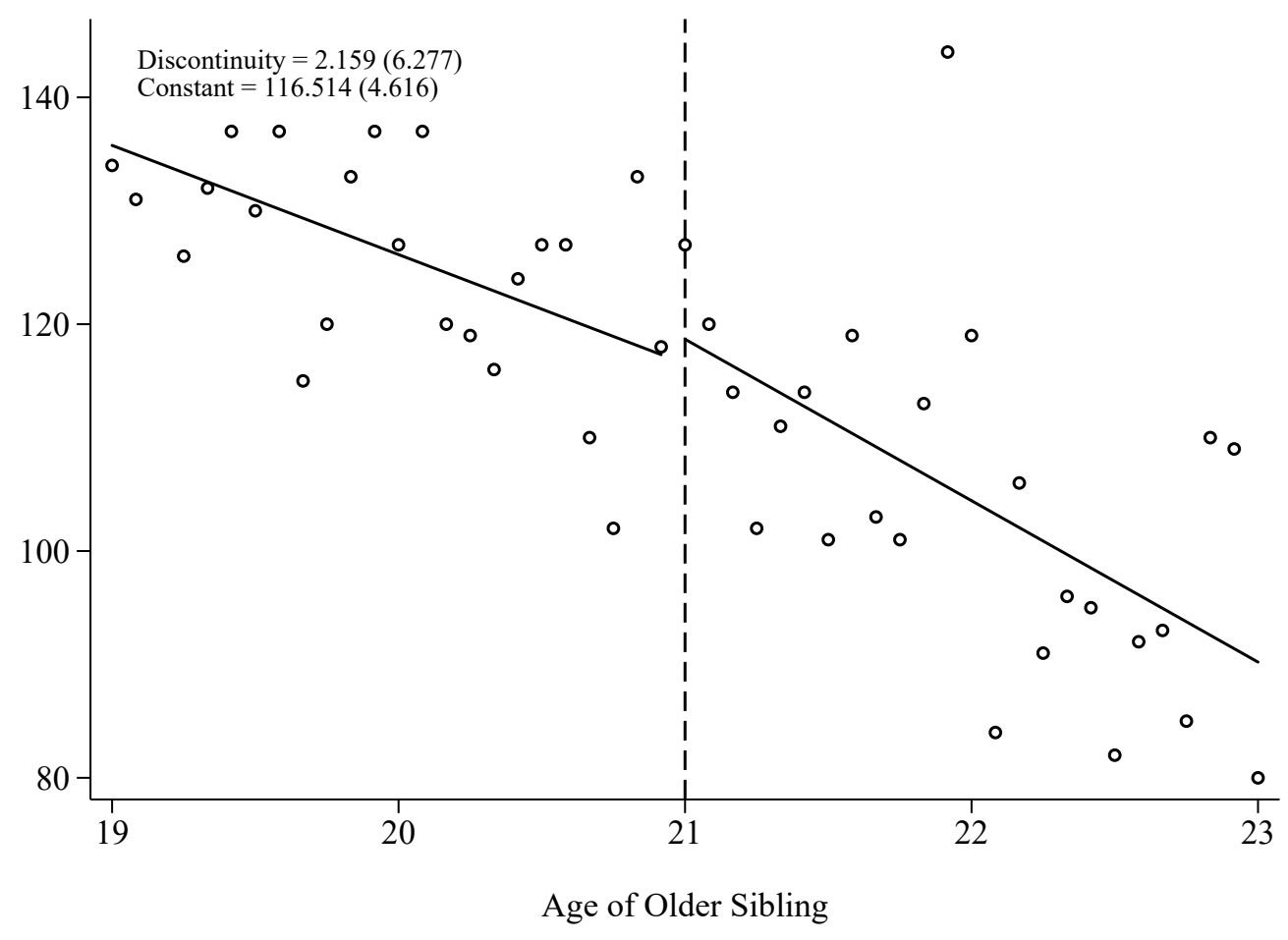

Notes: Y-axis shows the count of sibling-pairs with each running variable value (age in months of older sibling). Point estimates and standard errors are from a regression of the number of observations in each bin on the centered-at-21 running variable, the treatment cutoff, and their interaction (estimated with individual level data). 
Figure A3: Robustness to Alternative Specifications

(Outcome $=$ Prob. of Any Binge Drinking)

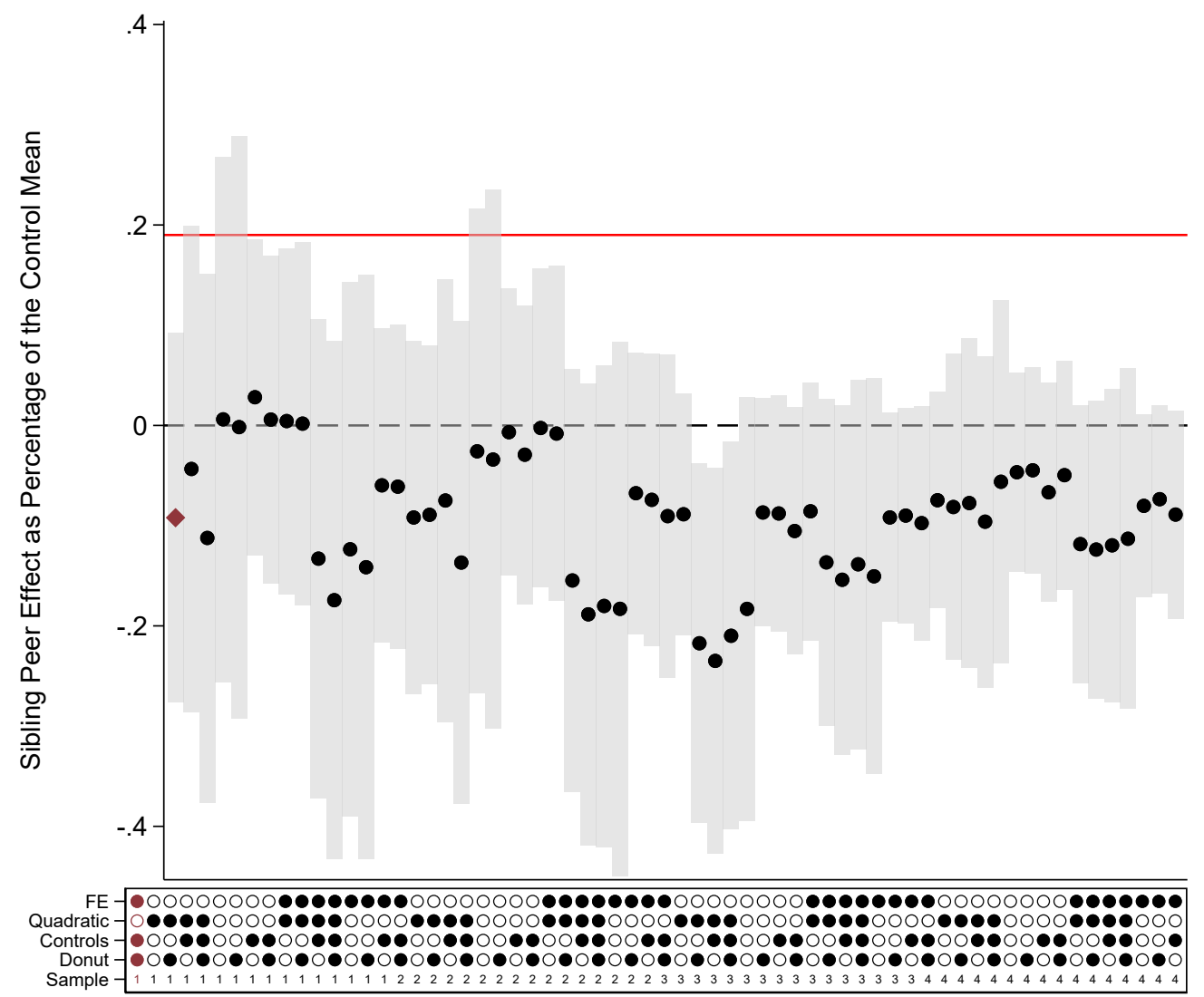

Notes: Figure shows point estimates and confidence intervals from various specifications in Table 3, all with an indicator for any binge days as the outcome, and all scaled by the pre-cutoff mean (constant in the corresponding regression on the centered-at-zero running variable, the treatment cutoff, and their interaction). Red line shows the point estimate from Eisenberg et al. (2014) for comparison. "Sample" refers to different subsets of sibling pairs, defined by (i) whether they live together, and (ii) whether they are the oldest two siblings in the household (or family). $1=$ same household, oldest two siblings in family. 2 = same household, peer is closest older sibling but not necessarily the only older sibling. $3=$ siblings do not necessarily live together, siblings are the oldest two siblings in the family. $4=$ siblings do not necessarily live together, peer is closest older sibling but not necessarily the only older sibling. 
Figure A4: Robustness to Alternative Specifications

(Outcome $=$ Count of Binge Drinking Days)

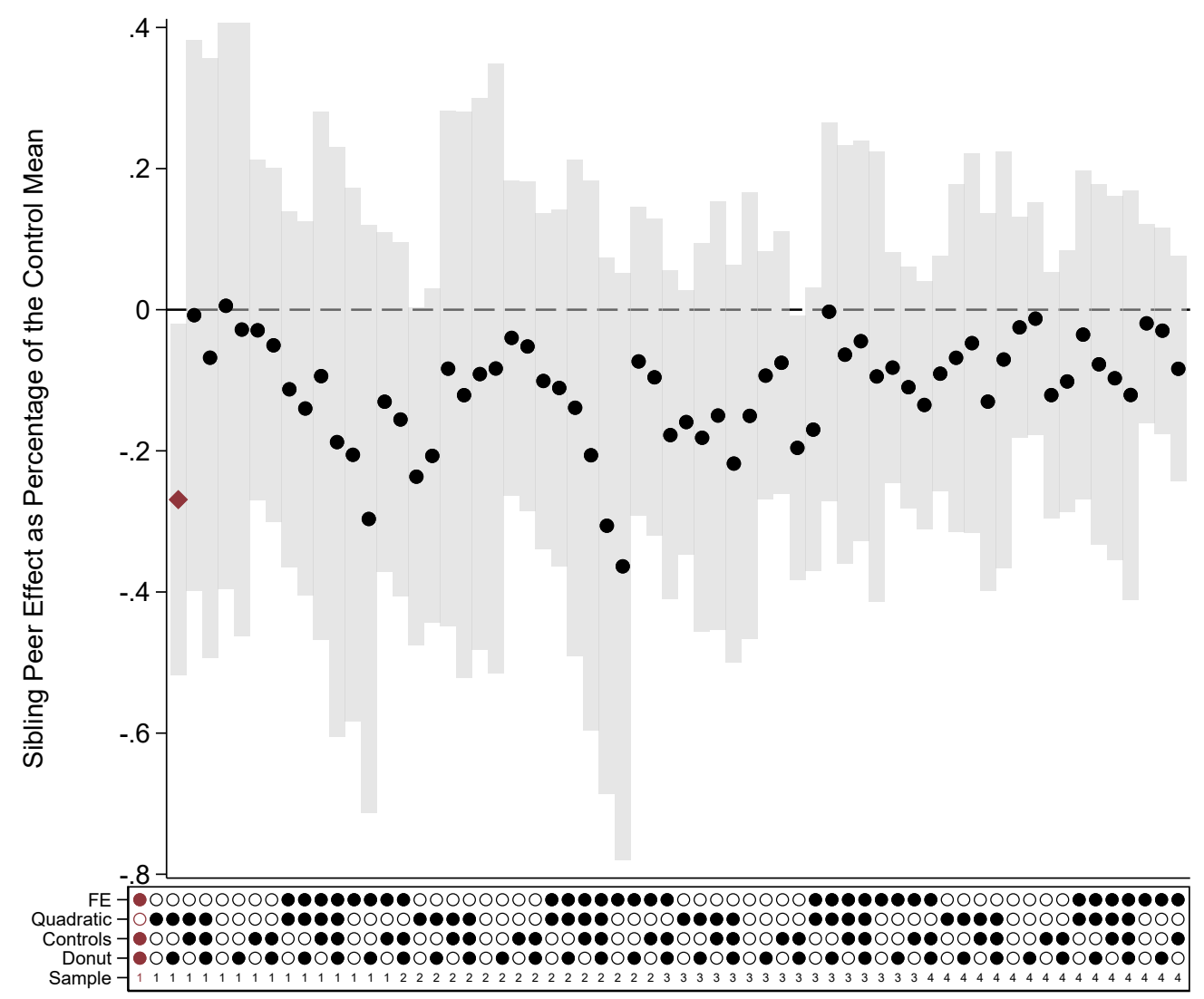

Notes: Figure shows point estimates and confidence intervals from various specifications in Table 3, all with the count of binge drinking days as the outcome, and all scaled by the pre-cutoff mean (constant in the corresponding regression on the centered-at-zero running variable, the treatment cutoff, and their interaction). "Sample" refers to different subsets of sibling pairs, defined by (i) whether they live together, and (ii) whether they are the oldest two siblings in the household (or family). 1 = same household, oldest two siblings in family. 2 = same household, peer is closest older sibling but not necessarily the only older sibling. 3 = siblings do not necessarily live together, siblings are the oldest two siblings in the family. 4 $=$ siblings do not necessarily live together, peer is closest older sibling but not necessarily the only older sibling. 
Figure A5: Time Spent with Older Siblings in the ATUS
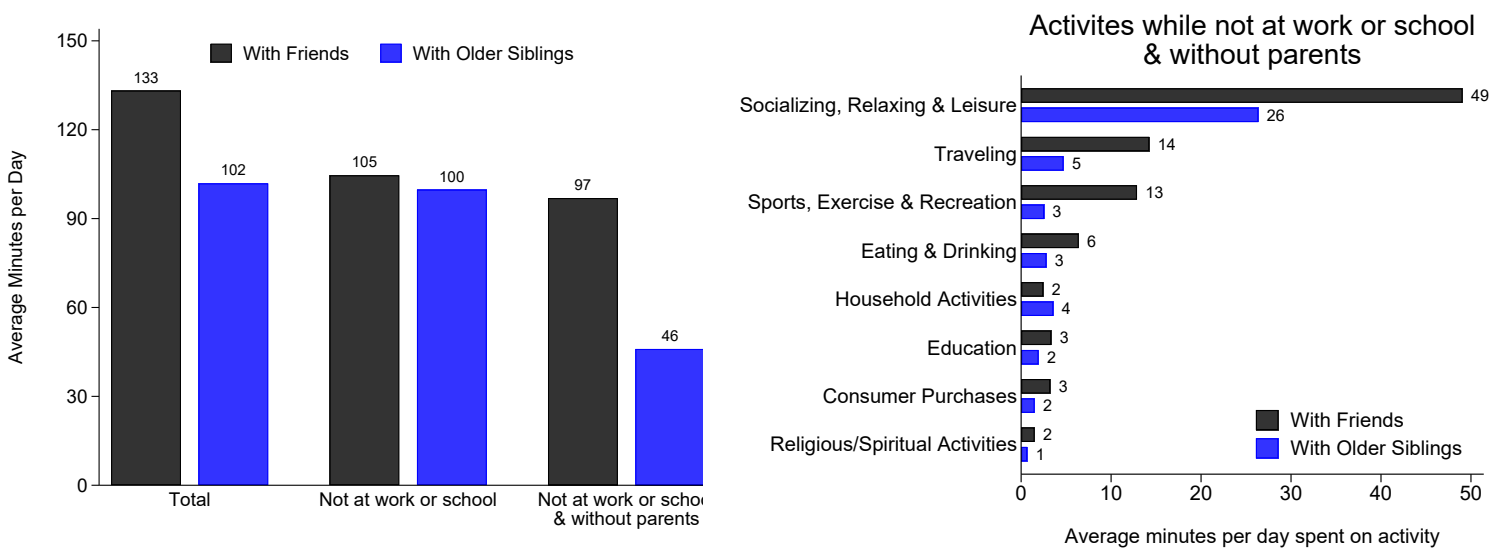

Notes: Descriptive statistics are from a sample of 2,795 respondents in the 2003-2019 waves of the ATUS who have 1 older siblings under the age of 23 in their household. Each panel shows the average (across respondent) time per day spent with either friends (black, left bars in each pair in the left panel and top bars in each pair in the right panel) or older siblings (blue, right bars in each pair in the left panel and bottom bars in each pair in the right panel) in various categories. 
Table A1: Correlations in Alcohol Consumption Between Siblings

\begin{tabular}{lcccc}
\hline \hline & \multicolumn{3}{c}{ Younger Sibling Consumption } \\
\cline { 2 - 4 } & \multicolumn{2}{c}{ Count of Drinking Days } & \multicolumn{2}{c}{ Any Drinking Days } \\
\hline Older Sibling Consumption & $0.161^{* * *}$ & $0.136^{* * *}$ & $0.178^{* * *}$ & $0.168^{* * *}$ \\
& $(0.020)$ & $(0.019)$ & $(0.018)$ & $(0.016)$ \\
Mean & 1.938 & 2.356 & 0.374 & 0.421 \\
Observations & 3,808 & 6,096 & 3,808 & 6,096 \\
\hline Older Sibling Consumption & Count of Binge Drinking Days & Any Binge Drinking Days \\
Mean & $0.162^{* * *}$ & $0.132^{* * *}$ & $0.165^{* * *}$ & $0.140^{* * *}$ \\
Observations & $(0.026)$ & $(0.021)$ & $(0.019)$ & $(0.016)$ \\
\hline Lag & 0.881 & 1.084 & 0.198 & 0.236 \\
\hline \hline
\end{tabular}

Notes: Each model has the younger sibling's consumption as the outcome and the older sibling's consumption as the covariate of interest. Model 1 uses the contemporaneous consumption of the older sibling and excludes sibling pairs in which the older sibling was interviewed after the younger sibling. Model 2 uses the lagged (prior survey year) consumption. All models are estimated via OLS with cluster robust standard errors at the household level and are limited to households with exactly two NLSY97 respondent siblings, in which the older sibling is 23 years old or younger. All models include a vector of controls for both siblings similar to those described in Section 2. Means of each outcome (for younger siblings) are shown for each model. $+,{ }^{*}, * *$, and ${ }^{* * *}$ denote statistical significance at the $10 \%, 5 \%, 1 \%$, and $0.1 \%$ levels, respectively. 
Table A2: Smoothness of Covariates at Cutoff

\begin{tabular}{lcccc}
\hline \hline & \multicolumn{4}{c}{ Predicted Outcomes } \\
\cline { 2 - 5 } & Drinking & Any & Binge & Any Binge \\
& Days & Drinking Days & Drinking Days & Binge Days $)$ \\
\hline Sibling 21+ & -0.024 & -0.004 & 0.007 & -0.001 \\
& $(0.083)$ & $(0.009)$ & $(0.053)$ & $(0.008)$ \\
Constant & $2.406^{* * *}$ & $0.449^{* * *}$ & $1.142^{* * *}$ & $0.254^{* * *}$ \\
& $(0.090)$ & $(0.010)$ & $(0.061)$ & $(0.009)$ \\
\hline$N$ & 4373 & 4373 & 4369 & 4369 \\
\hline \hline
\end{tabular}

Notes: Outcomes are predicted values from a regression of the relevant consumption measure on the month and year of the survey, the race of the respondent, the gender of the respondent and siblings, educational attainment and enrollment of the respondent, geography (urban/rural, census region), household size, AFQT score of the respondent, an indicator for whether or not the respondent has children, and an indicator for whether the respondent worked in the past year. Results shown are from regressions of these predicted values on the age of the older sibling in months, an indicator for whether the older sibling is over 21 , and their interaction. Standard errors are bootstrapped. $+,{ }^{*}, * *$, and $* * *$ denote statistical significance at the $10 \%, 5 \%, 1 \%$, and $0.1 \%$ levels, respectively. 
Table A3: Discontinuities in Older Sibling Alcohol Consumption in Subgroups, Binge Days, Inverse Propensity Score Weighted

\begin{tabular}{|c|c|c|c|c|}
\hline & \multicolumn{2}{|c|}{ Parental Education } & \multicolumn{2}{|c|}{ Household Income } \\
\hline & $<\mathrm{HS}$ & $\geq \mathrm{HS}$ & $<$ Median & $\geq$ Median \\
\hline \multirow[t]{2}{*}{ Age $21+$} & 0.239 & $0.649^{* * *}$ & 0.055 & $0.895^{*}$ \\
\hline & $(0.353)$ & $(0.180)$ & $(0.153)$ & $(0.385)$ \\
\hline Control Mean & 1.308 & 1.787 & 1.440 & 1.767 \\
\hline \multirow{3}{*}{ Observations } & 3,992 & 8,085 & 8,651 & 5,009 \\
\hline & \multicolumn{2}{|c|}{ Older Sibling's School Enrollment } & \multicolumn{2}{|c|}{ Older Sibling's Sex } \\
\hline & Enrolled & Not Enrolled & Male & Female \\
\hline \multirow[t]{2}{*}{ Age $21+$} & $0.464^{* *}$ & $0.504^{* *}$ & $0.527^{* *}$ & $0.321^{* *}$ \\
\hline & $(0.168)$ & $(0.162)$ & $(0.192)$ & $(0.123)$ \\
\hline Control Mean & 1.495 & 1.650 & 2.220 & 1.022 \\
\hline \multirow[t]{4}{*}{ Observations } & 6,560 & 10,041 & 8,127 & 8,474 \\
\hline & \multicolumn{2}{|c|}{ Race } & & \\
\hline & Black or & Non-Black \& & & \\
\hline & Hispanic & Non-Hispanic & & \\
\hline \multirow[t]{2}{*}{ Age $21+$} & 0.162 & $0.689^{* * *}$ & & \\
\hline & $(0.198)$ & $(0.169)$ & & \\
\hline Control Mean & 1.238 & 1.946 & & \\
\hline Observations & 7,206 & 9,395 & & \\
\hline
\end{tabular}

Notes: Controls include the month and year of the survey, the gender and age of the respondent and siblings, race of respondents, educational attainment and enrollment of respondents, geography (urban/rural, census region), household size, AFQT score of the respondent, an indicator for whether or not the respondent has children, and an indicator for whether the respondent worked in the past year. The same controls are used to estimate the propensity scores. Variables used to define the subgroups are omitted from the list of controls. All models are estimated in the corresponding subgroup of a sample of NLSY97 respondents who are the oldest siblings currently residing in their household who are between the ages of 19 and 23 . The median household income is $\$ 53,515$. Standard errors in all models are bootstrapped with 1000 replications. Re-sampling is at the youngersibling level (a given younger sibling typically appears in multiple waves with the same older sibling). Age is centered at 21 years. $+,{ }^{*}, * *$, and ${ }^{* * *}$ denote statistical significance at the $10 \%, 5 \%, 1 \%$, and $0.1 \%$ levels, respectively. 
Table A4: Reduced Form in Subgroups, Binge Days, Inverse Propensity Score Weighted

\begin{tabular}{|c|c|c|c|c|}
\hline & \multicolumn{2}{|c|}{ Parental Education } & \multicolumn{2}{|c|}{ Household Income } \\
\hline & $<\mathrm{HS}$ & $\geq \mathrm{HS}$ & $<$ Median & $\geq$ Median \\
\hline \multirow[t]{2}{*}{ Sibling 21+ } & -0.007 & $-0.419^{*}$ & 0.048 & -0.970 \\
\hline & $(0.471)$ & $(0.209)$ & $(0.287)$ & $(0.601)$ \\
\hline Control Mean & 0.755 & 1.336 & 0.779 & 1.906 \\
\hline \multirow[t]{3}{*}{ Observations } & 1,045 & 2,206 & 875 & 875 \\
\hline & \multicolumn{2}{|c|}{ Older Sibling's School Enrollment } & \multicolumn{2}{|c|}{ Older Sibling's Sex } \\
\hline & Enrolled & Not Enrolled & Male & Female \\
\hline \multirow{2}{*}{ Sibling $21+$} & -0.186 & $-0.759^{*}$ & $-0.604^{* *}$ & 0.072 \\
\hline & $(0.252)$ & $(0.331)$ & $(0.223)$ & $(0.234)$ \\
\hline Control Mean & 1.020 & 1.367 & 1.383 & 0.880 \\
\hline \multirow[t]{3}{*}{ Observations } & 2,184 & 2,074 & 2,266 & 2,012 \\
\hline & \multicolumn{2}{|c|}{ Race } & \multicolumn{2}{|c|}{ Sibling Sex Composition } \\
\hline & $\begin{array}{l}\text { Black or } \\
\text { Hispanic }\end{array}$ & $\begin{array}{l}\text { Non-Black \& } \\
\text { Non-Hispanic }\end{array}$ & Same & Different \\
\hline Age $21+$ & $\begin{array}{l}-0.204 \\
(0.153)\end{array}$ & $\begin{array}{l}-0.596 \\
(0.376)\end{array}$ & $\begin{array}{c}-0.573^{* *} \\
(0.209)\end{array}$ & $\begin{array}{l}-0.008 \\
(0.232)\end{array}$ \\
\hline Control Mean & 0.637 & 1.652 & 1.310 & 0.967 \\
\hline Observations & 2,020 & 2,258 & 2,379 & 1,899 \\
\hline
\end{tabular}

Notes: Controls include the month and year of the survey, the gender and age of the respondent and siblings, race of respondents, educational attainment and enrollment of respondents, geography (urban/rural, census region), household size, AFQT score of the respondent, an indicator for whether or not the respondent has children, and an indicator for whether the respondent worked in the past year. The same controls are used to estimate the propensity scores. Variables used to define the subgroups are omitted from the list of controls. All models are estimated in the corresponding subgroup of a sample of NLSY97 respondents who have exactly one older sibling in their household, and where that older sibling is between the ages of 19 and 23 . The median household income is $\$ 53,515$ in this sample. Standard errors in all models are bootstrapped with 1000 replications. Re-sampling is at the younger-sibling level (a given younger sibling typically appears in multiple waves with the same older sibling). Sibling age is centered at 21 years. $+,{ }^{*}, * *$, and $* * *$ denote statistical significance at the $10 \%, 5 \%, 1 \%$, and $0.1 \%$ levels, respectively. 
Table A5: Effect of Younger Sibling on Older Sibling

\begin{tabular}{lcccc}
\hline \hline & $\begin{array}{c}\text { Drinking } \\
\text { Days }\end{array}$ & $\begin{array}{c}\text { Any } \\
\text { Drinking Days }\end{array}$ & $\begin{array}{c}\text { Binge } \\
\text { Drinking Days }\end{array}$ & $\begin{array}{c}\text { Any Binge } \\
\text { Drinking Days }\end{array}$ \\
\hline Sibling 21+ & \multicolumn{2}{c}{ Two Youngest Siblings Living in the Same Household } \\
& $(0.465)$ & 0.004 & 0.065 & 0.056 \\
Control Mean & 4.743 & $0.034)$ & $(0.257)$ & $(0.036)$ \\
Observations & 2,380 & 2,380 & 1.854 & 0.374 \\
\hline & \multicolumn{5}{c}{ Two Siblings Living in the Same Household } \\
\hline Sibling 21+ & -0.005 & 0.017 & -0.014 & $0.062^{*}$ \\
Control Mean & $(0.325)$ & $(0.026)$ & $(0.214)$ & $(0.029)$ \\
Observations & 4.342 & 0.615 & 1.643 & 0.338 \\
\hline & 3,758 & 3,758 & 3,702 & 3,702 \\
\hline Sibling 21+ & 0.006 & 0.007 & -0.112 & 0.001 \\
Control Mean & $(0.227)$ & $(0.017)$ & $(0.136)$ & $0.018)$ \\
Observations & 4.691 & 0.694 & 1.726 & 7,398 \\
\hline Sibling 21+ & 7,557 & 7,557 & 7,398 & 0.011 \\
Control Mean & -0.056 & 0.002 & Two Siblings & $0.013)$ \\
Observations & 13,467 & $(0.013)$ & -0.000 & 13,145 \\
\hline \hline
\end{tabular}

Notes: The first panel is estimated in a sample of NLSY97 respondents who have exactly one younger sibling in their household, and where that younger sibling is between the ages of 19 and 23. The second panel is estimated in a sample of NLSY97 respondents who are the second youngest siblings, where their younger sibling is between the ages of 19 and 23, and the younger sibling may not currently reside in the same household as the respondent. The third panel is estimated in a sample of NLSY97 respondents who have one or more younger siblings in their household where the closest younger sibling to the respondent is between the ages of 19 and 23. The last panel is estimated in a sample of NLSY respondents who have one or more younger siblings, where the closest younger sibling to the respondent is between the ages of 19 and 23, and the closest younger sibling may not currently reside in the same household as the respondent. Controls include the month and year of the survey, the gender and age of the respondent and siblings, race of respondents, educational attainment and enrollment of respondents, geography (urban/rural, census region), household size, AFQT score of the respondent, an indicator for whether the respondent has children, and an indicator for whether the respondent worked in the past year. All models include cluster robust standard errors at individual level. Sibling age is centered at 21 years. $+,{ }^{*}, * *$, and $* * *$ denote statistical significance at the $10 \%, 5 \%, 1 \%$, and $0.1 \%$ levels, respectively. 
Table A6: Switcher and Non-Switcher Characteristics

\begin{tabular}{|c|c|c|c|}
\hline & $\begin{array}{l}\text { Switchers } \\
\text { mean (sd) }\end{array}$ & $\begin{array}{l}\text { Non-switchers } \\
\text { mean (sd) }\end{array}$ & p-value \\
\hline Age difference between the siblings & $\begin{array}{c}2.81 \\
(1.36)\end{array}$ & $\begin{array}{c}3.01 \\
(1.65)\end{array}$ & 0.00 \\
\hline Siblings have same gender & $\begin{array}{c}0.55 \\
(0.50)\end{array}$ & $\begin{array}{c}0.53 \\
(0.50)\end{array}$ & 0.04 \\
\hline \multicolumn{4}{|l|}{ Younger Sibling's Characteristics: } \\
\hline Female & $\begin{array}{c}0.47 \\
(0.50)\end{array}$ & $\begin{array}{c}0.48 \\
(0.50)\end{array}$ & 0.44 \\
\hline Race: Black & $\begin{array}{c}0.27 \\
(0.44)\end{array}$ & $\begin{array}{c}0.24 \\
(0.43)\end{array}$ & 0.04 \\
\hline Race: Hispanic & $\begin{array}{c}0.24 \\
(0.43)\end{array}$ & $\begin{array}{c}0.24 \\
(0.42)\end{array}$ & 0.75 \\
\hline Urban & $\begin{array}{c}0.78 \\
(0.41)\end{array}$ & $\begin{array}{c}0.75 \\
(0.43)\end{array}$ & 0.01 \\
\hline AFQT score & $\begin{array}{c}46,037.04 \\
(29,391.96)\end{array}$ & $\begin{array}{c}42,094.33 \\
(28,584.32)\end{array}$ & 0.00 \\
\hline Household Income & $\begin{array}{r}\$ 66,654.55 \\
(57,999.39)\end{array}$ & $\begin{array}{l}\$ 52,071.82 \\
(48,741.99)\end{array}$ & 0.00 \\
\hline $\mathrm{N}$ & 3716 & 1859 & \\
\hline N Sibling Pairs & 1180 & 1423 & \\
\hline
\end{tabular}

Notes: FE estimates of the effect of an older sibling turning 21 are identified only by groups who have variation in this treatment, i.e., younger siblings who show up in our sample at least once before their older sibling turns 21 and at least once after. This table compares these "switcher" sibling pairs to the corresponding "non-switcher" sibling pairs, in our main analysis sample (younger sibling is a NLSY-respondent, older sibling is between the ages of 19 and 23, siblings are the two oldest siblings in the household). The third column displays the p-value for the null hypothesis that the means in the switcher and non-switcher groups are equivalent. 
Table A7: Switcher and Non-Switcher Characteristics in an Alternative Sample

\begin{tabular}{|c|c|c|c|}
\hline & $\begin{array}{l}\text { Switchers } \\
\text { mean (sd) }\end{array}$ & $\begin{array}{l}\text { Non-switchers } \\
\text { mean (sd) }\end{array}$ & p-value \\
\hline Age difference between the siblings & $\begin{array}{l}2.65 \\
(1.32)\end{array}$ & $\begin{array}{c}4.03 \\
(2.10)\end{array}$ & 0.00 \\
\hline Siblings have same gender & $\begin{array}{c}0.52 \\
(0.50)\end{array}$ & $\begin{array}{c}0.53 \\
(0.50)\end{array}$ & 0.68 \\
\hline \multicolumn{4}{|l|}{ Younger Sibling's Characteristics: } \\
\hline Female & $\begin{array}{c}0.50 \\
(0.50)\end{array}$ & $\begin{array}{c}0.47 \\
(0.50)\end{array}$ & 0.18 \\
\hline Race: Black & $\begin{array}{c}0.25 \\
(0.43)\end{array}$ & $\begin{array}{c}0.25 \\
(0.43)\end{array}$ & 0.93 \\
\hline Race: Hispanic & $\begin{array}{c}0.20 \\
(0.40)\end{array}$ & $\begin{array}{c}0.28 \\
(0.45)\end{array}$ & 0.00 \\
\hline Urban & $\begin{array}{c}0.76 \\
(0.43)\end{array}$ & $\begin{array}{c}0.76 \\
(0.43)\end{array}$ & 0.76 \\
\hline AFQT score & $\begin{array}{c}45,620.70 \\
(28,991.13)\end{array}$ & $\begin{array}{c}40,877.99 \\
(26,712.87)\end{array}$ & 0.00 \\
\hline Household Income & $\begin{array}{l}\$ 53,699.29 \\
(56,351.16)\end{array}$ & $\begin{array}{l}\$ 47,828.96 \\
(48,448.64)\end{array}$ & 0.09 \\
\hline$\overline{\mathrm{N}}$ & 4240 & 345 & \\
\hline N Sibling Pairs & 1788 & 278 & \\
\hline
\end{tabular}

Notes: FE estimates of the effect of an older sibling turning 21 are identified only by groups who have variation in this treatment, i.e., younger siblings who show up in our sample at least once before their older sibling turns 21 and at least once after. This table compares these "switcher" sibling pais to the corresponding "nonswitcher" sibling pairs, in an alternative sample that does not require the siblings to live together (i.e., here the younger sibling is a NLSY-respondent, the older sibling is between the ages of 19 and 23, and the siblings are the two oldest siblings in the family). The third column displays the p-value for the null hypothesis that the means in the switcher and non-switcher groups are equivalent. 
Table A8: Robustness to mean-squared error optimal bandwidth from Calonico et al. (2020) and bias-corrected robust confidence intervals from Calonico et al. (2014, 2018).

\begin{tabular}{ccccc}
\hline \hline & \multicolumn{4}{c}{ Count of Binge Drinking Days } \\
& $(1)$ & $(2)$ & $(3)$ & $(4)$ \\
\hline Sibling 21+ & $-0.429^{* * *}$ & $-0.355^{* *}$ & -0.118 & -0.129 \\
& {$[-0.598,-0.261]$} & {$[-0.529,-0.180]$} & {$[-0.612,0.372]$} & {$[-0.612,0.597]$} \\
Bandwidth & 16.64 & 24.00 & 22.86 & 24.00 \\
Observations & 2874 & 4124 & 3931 & 4124 \\
\hline \multicolumn{5}{c}{ Any Binge Drinking Days } \\
\hline Sibling 21+ & $-0.027^{*}$ & $-0.029^{*}$ & -0.000 & -0.000 \\
Bandwidth & $1-0.048,-0.005]$ & {$[-0.056,-0.002]$} & {$[-0.061,0.075]$} & {$[-0.069,0.107]$} \\
Observations & 2555 & 24.00 & 24.59 & 24.00 \\
\hline FE & $\mathrm{X}$ & 4124 & 4278 & 4124 \\
Quadratic & $\mathrm{X}$ & $\mathrm{X}$ & & $\mathrm{X}$ \\
Controls & $\mathrm{X}$ & $\mathrm{X}$ & $\mathrm{X}$ & $\mathrm{X}$ \\
Donut & $\mathrm{X}$ & $\mathrm{X}$ & \\
\hline \hline
\end{tabular}

Notes: This table displays specifications using a mean-squared error optimal bandwidth from Calonico et al. (2020) (columns 1 and 3), a triangular kernel (all columns), and bias-corrected robust confidence intervals (all columns) as described in Calonico et al. (2014, 2018). Controls include the month and year of the survey, the gender and age of the respondent and siblings, race of respondents, educational attainment and enrollment of respondents, geography (urban/rural, census region), household size, AFQT score of the respondent, an indicator for whether or not the respondent has children, and an indicator for whether the respondent worked in the past year. All models use triangular kernels and include bias-corrected robust $95 \%$ confidence intervals described in Calonico et al. (2014, 2018), where the standard errors are cluster robust at individual level. Models 1 and 3 use MSE-optimal bandwidths from Calonico et al. (2020), and the other models use our ad-hoc 24 month bandwidth. Sibling age is centered at 21 years. $+,^{*}, * *$, and $* * *$ denote statistical significance at the $10 \%, 5 \%, 1 \%$, and $0.1 \%$ levels, respectively. 
Table A9: Parenting style changes at the cutoff

\begin{tabular}{|c|c|c|c|c|c|}
\hline & \multicolumn{5}{|c|}{ Degree of Parental Monitoring } \\
\hline & (1) & $(2)$ & $(3)$ & $(4)$ & $(5)$ \\
\hline \multirow{2}{*}{ Sibling $21+$} & -0.255 & $-0.726^{*}$ & -0.334 & -0.421 & -0.208 \\
\hline & $(0.321)$ & $(0.353)$ & $(0.507)$ & $(0.292)$ & $(0.294)$ \\
\hline Control Mean & 9.031 & 9.031 & 9.031 & 9.031 & 9.031 \\
\hline \multirow[t]{2}{*}{ Observations } & 1,467 & 1,467 & 1,467 & 1,937 & 1,493 \\
\hline & \multicolumn{5}{|c|}{ Parents: Authoritarian/Authoritative } \\
\hline \multirow[t]{2}{*}{ Sibling 21+ } & -0.009 & -0.001 & -0.013 & 0.007 & -0.009 \\
\hline & $(0.025)$ & $(0.023)$ & $(0.041)$ & $(0.024)$ & $(0.024)$ \\
\hline Control Mean & 0.251 & 0.251 & 0.251 & 0.251 & 0.251 \\
\hline Observations & 4,317 & 4,317 & 4,317 & 5,575 & 4,408 \\
\hline $\mathrm{FE}$ & $\mathrm{X}$ & & $\mathrm{X}$ & $\mathrm{X}$ & $\mathrm{X}$ \\
\hline Quadratic & & & $\mathrm{X}$ & & \\
\hline Controls & $\mathrm{X}$ & $\mathrm{X}$ & $\mathrm{X}$ & & $\mathrm{X}$ \\
\hline Donut & $\mathrm{X}$ & $\mathrm{X}$ & $\mathrm{X}$ & $\mathrm{X}$ & \\
\hline
\end{tabular}

Notes: Controls include the month and year of the survey, the gender and age of the respondent and siblings, race of respondents, educational attainment and enrollment of respondents, geography (urban/rural, census region), household size, AFQT score of the respondent, an indicator for whether or not the respondent has children, and an indicator for whether the respondent worked in the past year. All models are estimated in a sample of NLSY97 respondents who are the second oldest siblings currently residing in their household, where the oldest sibling is between the ages of 19 and 23. All models include cluster robust standard errors at individual level. Sibling age is centered at 21 years. $+,{ }^{*}, * *$, and ${ }^{* * *}$ denote statistical significance at the $10 \%, 5 \%, 1 \%$, and $0.1 \%$ levels, respectively. 
Table A10: ATUS Sample Summary Statistics

\begin{tabular}{lcccc}
\hline \hline & Mean & SD & Min & Max \\
\hline Respondent Characteristics: & & & & \\
Age & & & & \\
Female & 17.15 & $(1.76)$ & 15.0 & 22.0 \\
In high school & 0.49 & $(0.50)$ & 0.0 & 1.0 \\
In college & 0.58 & $(0.49)$ & 0.0 & 1.0 \\
Employed & 0.18 & $(0.39)$ & 0.0 & 1.0 \\
Surveyed on a weekend or holiday & 0.38 & $(0.49)$ & 0.0 & 1.0 \\
Age of closest older sibling & 0.31 & $(0.46)$ & 0.0 & 1.0 \\
& 19.86 & $(1.89)$ & 16.0 & 23.0 \\
Minutes Spent (during ATUS-diary day): & & & & \\
\hline & & & & \\
At home & & & & \\
At school & 333.69 & $(221.19)$ & 0.0 & 1440.0 \\
At work & 168.94 & $(223.88)$ & 0.0 & 1020.0 \\
Alone & 67.23 & $(163.28)$ & 0.0 & 890.0 \\
With an older sibling & 223.38 & $(196.42)$ & 0.0 & 1370.0 \\
With a parent & 103.71 & $(171.45)$ & 0.0 & 1200.0 \\
With a friend & 147.03 & $(192.08)$ & 0.0 & 1200.0 \\
With anyone else & 135.97 & $(208.73)$ & 0.0 & 1140.0 \\
N & 186.36 & $(227.81)$ & 0.0 & 1210.0 \\
\hline \hline
\end{tabular}

Notes: Summary statistics from time-diaries for all ATUS respondents in the 2003-2019 waves who lived with one older sibling 23 years old or younger. All summary statistics are calculated using survey weights. Data from Hofferth et al. (2020). 